\title{
In situ aerosol-size distributions and clear-column radiative closure during ACE-2
}

By D. R. COLlinS ${ }^{1}$, H. H. JONSSON ${ }^{2}$, J. H. SEINFELD ${ }^{1 *}$, R. C. FLAGAN ${ }^{1}$, S. GASSÓ ${ }^{3}$, D. A. $\mathrm{HEGG}^{3}$, P. B. RUSSELL ${ }^{4}$, B. SCHMID ${ }^{5}$, J. M. LIVINGSTON ${ }^{6}$, E. ÖSTRÖM ${ }^{7}$, K. J. NOONE ${ }^{8}$, L. M. RUSSELL ${ }^{9}$ and J. P. PUTAUD ${ }^{10},{ }^{1}$ California Institute of Technology, 1200 E. California Blvd, Mail code 210-41, Pasadena, CA 91125; ${ }^{2}$ Naval Postgraduate School, Monterey, CA; ${ }^{3}$ University of Washington, Seattle, WA; ${ }^{4}$ NASA Ames Research Center, Moffett Field, CA; ${ }^{5}$ Bay Area Environmental Research Institute, San Fransisco, CA; ${ }^{6} S R I$ International, Menlo Park, CA, USA; ${ }^{7} U K$ Meteorological Office, Beaufort Park, UK; ${ }^{8}$ Stockholm University, Sweden; ${ }^{9}$ Princeton University, Princeton, NJ, USA;

${ }^{10}$ Joint Research Centre, Ispra, Italy

(Manuscript received 28 December 1999; in final form 15 September 1999)

\section{ABSTRACT}

As part of the second Aerosol Characterization Experiment (ACE-2) during June and July of 1997, aerosol-size distributions were measured on board the CIRPAS Pelican aircraft through the use of a DMA and 2 OPCs. During the campaign, the boundary-layer aerosol typically possessed characteristics representative of a background marine aerosol or a continentally influenced aerosol, while the free-tropospheric aerosol was characterized by the presence or absence of a Saharan dust layer. A range of radiative closure comparisons were made using the data obtained during vertical profiles flown on 4 missions. Of particular interest here are the comparisons made between the optical properties as determined through the use of measured aerosol-size distributions and those measured directly by an airborne 14-wavelength sunphotometer and 3 nephelometers. Variations in the relative humidity associated with each of the direct measurements required consideration of the hygroscopic properties of the aerosol for size-distribution-based calculations. Simultaneous comparison with such a wide range of directly-measured optical parameters not only offers evidence of the validity of the physicochemical description of the aerosol when closure is achieved, but also provides insight into potential sources of error when some or all of the comparisons result in disagreement. Agreement between the derived and directly-measured optical properties varied for different measurements and for different cases. Averaged over the 4 case studies, the derived extinction coefficient at $525 \mathrm{~nm}$ exceeded that measured by the sunphotometer by $2.5 \%$ in the clean boundary layer, but underestimated measurements by $13 \%$ during pollution events. For measurements within the free troposphere, the mean derived extinction coefficient was $3.3 \%$ and $17 \%$ less than that measured by the sunphotometer during dusty and non-dusty conditions, respectively. Likewise, averaged discrepancies between the derived and measured scattering coefficient were $-9.6 \%,+4.7 \%,+17 \%$, and $-41 \%$ for measurements within the clean boundary layer, polluted boundary layer, free troposphere with a dust layer, and free troposphere without a dust layer, respectively. Each of these quantities, as well as the majority of the $>100$ individual comparisons from which they were averaged, were within estimated uncertainties.

\footnotetext{
* Corresponding author.
}

e-mail: seinfeld@its.caltech.edu 


\section{Introduction}

Despite an intensive effort to understand the effect of aerosols on regional and global scale radiation budgets, many questions remain unresolved. Among these are questions regarding regionally representative physical and chemical aerosol characteristics and the associated impact of the aerosol on the local radiation balance, directly, due to upscatter and absorption of solar radiation, and, indirectly, through altering cloud properties. Large scale field campaigns have proven to be particularly useful in providing answers in that they allow for simultaneous measurement of a broad spectrum of interrelated gas, aerosol, cloud, and radiation properties. Data resulting from these campaigns can ultimately be incorporated into models that predict radiative forcing resulting from potential changes in aerosol and precursor emissions and into retrieval algorithms necessary for evaluation of remote sensing data. Such models allow extrapolation of local observations to more extensive, climatically significant areas. Prerequisite to successful prediction of any kind, however, is the ability to demonstrate agreement between directly-measured optical and cloud formation characteristics and those calculated on the basis of simultaneously measured aerosol microphysical properties. This so-called closure has been attempted with varying degrees of success by a number of research groups using a variety of sets of over-determined measurements and computational techniques (Clarke et al., 1996; Hoff et al., 1996; Hegg et al., 1997; Howell and Huebert, 1998; Redemann et al., 1998).

The variety of measurements made during ACE-2 provided a unique opportunity to attempt a range of aerosol radiative closure comparisons. Among these comparisons, a distinction can be made between those of an individual optical measurement and the associated quantity calculated from the physicochemical properties of the aerosol, and those from multiple direct measurements. In theory, the latter type of comparison could be accomplished with no knowledge of aerosol microphysics. In practice, however, even for the relatively straightforward comparison between measured aerosol scattering and absorption coefficients and simultaneously measured extinction coefficient, an understanding of the aerosolsize distribution is necessary to account for such biases as the angular sensitivity associated with nephelometers, or the expected growth, evaporation, or loss of particles associated with either nephelometers or absorption photometers. The same conclusion is true for direct comparisons with satellite or lidar data, which, in general, require knowledge of such quantities as the aerosol scattering phase function and single scatter albedo, which, as before, could be measured directly, but in practice, generally require a description of the aerosol microphysics. As a result, essentially all potential comparisons, to some extent, necessitate an understanding of the aerosol itself. Assumptions made for specific classes of aerosols can be used in place of direct size distribution and composition measurements, but likely at the expense of accuracy. The focus here is on the radiative closure between directly-measured scattering and extinction coefficients and those calculated based on the aerosol-size distributions. Schmid et al. (2000) expand upon this analysis by utilizing the aerosolsize distributions described here to aid in the evaluation of closure between additional measurements.

The second Aerosol Characterization Experiment (ACE-2) was conducted in June and July of 1997 in the Northeastern Atlantic in a region bounded roughly by the Canary Islands of Spain to the south and Sagres, Portugal to the north. A more detailed overview of the objectives, experiments, and outcome of the campaign is described by Raes et al. (2000) and Verver et al. (2000). During the summer months, air masses arriving in the studied area have a variety of origins, including the central North Atlantic, Western Europe, and North Africa, which bring background marine, aged pollution, and mineral dust aerosols, respectively. During this campaign, the CIRPAS Pelican flew 21 scientific missions out of Tenerife, Spain (one of the Canary Islands) as part of the coordinated LAGRANGIAN, CLEARCOLUMN, and CLOUDYCOLUMN experiments, which are described in this issue by Johnson et al., Russell and Heintzenberg, and Brenguier et al.. The relatively large number of flights resulted in a data set sufficient to describe not only the average characteristics of each of the aerosol types described but also the variability observed within these broad categories. This paper discusses aerosol-size distributions measured on the Pelican during ACE-2 and clear column 
radiative closure for 4 flights that are thought to represent the range of conditions prevalent in the region of study.

\section{Instrumentation and analysis}

\subsection{Aerosol-size measurements}

The differential mobility analyzer (DMA) system used on board the Pelican was the Caltech Automated Classified Aerosol Detector (ACAD), which is the improved successor to a package operated during the MAST, ACE-1, and TARFOX experiments (Russell et al., 1996b). The key components of the instrument are a radial DMA designed for classification of particles smaller than a few tenths of a micrometer diameter, and a modified TSI 3010 condensation particle counter capable of a detection efficiency exceeding $90 \%$ for $4.5 \mathrm{~nm}$ diameter particles. Active flow controllers maintained each of the system's flow rates to within $1 \%$ of their specified values. A computercontrolled, high-resolution, 18-bit digital to analog chip was used to scan the voltage applied to the DMA over $45 \mathrm{~s}$. To compensate for the reduction in electric field strength sufficient to result in arcing within the DMA with decreasing air density, while at the same time extending the measured size range to the maximum particle size possible, the peak applied voltage was varied automatically. The resulting size range analyzed was approximately 5 to $190 \mathrm{~nm}$ and varied relatively little with changing altitude. The ACAD was calibrated prior to the ACE-2 period and accurately recovered both the peak size and total number concentration of monodisperse calibration aerosols as small as $7 \mathrm{~nm}$ diameter. The sample flow for the ACAD entered through a community inlet and subsequently passed through a cyclone with a nominal $2.5 \mu \mathrm{m}$ cut size, although this cutoff had a negligible effect on the small particles of interest.

2.1.2. PCASP. The first of two optical particle counters (OPCs) utilized during ACE-2 was the passive cavity aerosol spectrometer probe (PCASP-100X) manufactured by Particle Measuring Systems (PMS). The PCASP makes use of a large scattered light collection area to enable detection of particles as small as approximately $0.1 \mu \mathrm{m}$ diameter. The PCASP sample inlet is designed to minimize inertial particle losses, thereby enabling penetration and detection of particles exceeding $3 \mu \mathrm{m}$ diameter. As with all OPCs, inference of particle size with the PCASP is complicated by the fact that the light scattered by a particle is a function not only of its size, but also of its index of refraction and shape. To account for the influence of particle refractive index, the size calibration performed prior to ACE-2 using polystyrene latex particles (PSL, $m=$ $1.59-0 i$ ) was used along with Mie theory to calculate the expected scattered light intensity over the PCASP's collection area corresponding to each of the particle size bins. Several hundred effective calibrations were then generated for the range of complex refractive indices expected by iteratively calculating the particle size necessary to result in a collected light intensity equivalent to that calculated using the original PSL calibration. Fig. 1 shows the relationship between the size as calibrated with PSL and the corresponding effective calculated size. Underestimation of particle size based on PSL calibration, as seen in this figure, is representative of almost all relevant refractive indices. Assumed aerosol chemical composition, which is discussed below, along with the relative humidity within the instrument, is then used to determine a sampled particle's refractive index, from which size can be determined through the use of the generated effective calibrations.

Tandem differential mobility analyzer (TDMA) experiments conducted in the boundary layer at a site on Tenerife during ACE- 2 indicated that $80 \%$ or more of the particles were hygroscopic in nature, having wet diameters ( $\mathrm{RH} \sim 80-90 \%)$ typically in excess of 1.5 times larger than their

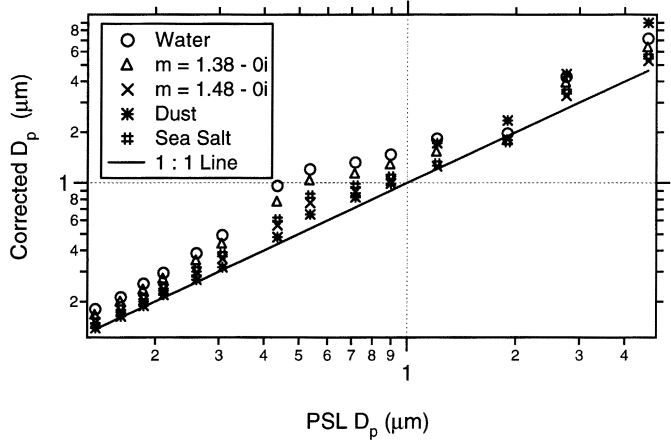

Fig. 1. Theoretical particle size required to result in the same collected light intensity in the PCASP as a PSL particle of a given size. 
corresponding dry diameters (RH $\sim 10 \%$ ) (Swietlicki et al., 2000). Particles of this type are expected to be spherical at the relative humidity range of approximately $70-90 \%$ characteristic of the boundary layer. While these particles will partially evaporate as a result of the heating associated with the PCASP as discussed below, they are expected to remain spherical since the corresponding range of instrument humidity is approximately $55-75 \%$, which is above the crystallization point for the species of interest. Therefore, for the boundary-layer aerosol, the Mie theory calculations performed are applicable. On the other hand, dust, crystalline salt, and externally mixed carbon particles present in the free troposphere are not necessarily spherical. To estimate the effect this would have on particle size assignment by the PCASP, the modeled phase functions of nonspherical particles described by Mishchenko et al. (1997) were considered. In general, the phase functions resulting from particles much smaller than the wavelength of light used $(633 \mathrm{~nm})$ closely approach those of ideal spheres. Assuming that larger, dust-like particles are spherical will result in an over-prediction of the phase function between about 30 and $80^{\circ}$, and an even larger under-prediction between approximately 90 and $150^{\circ}$, as shown in Fig. 2 for a distribution of particles thought to be representative of mineral dust. Fortunately, the PCASP collection geometry,

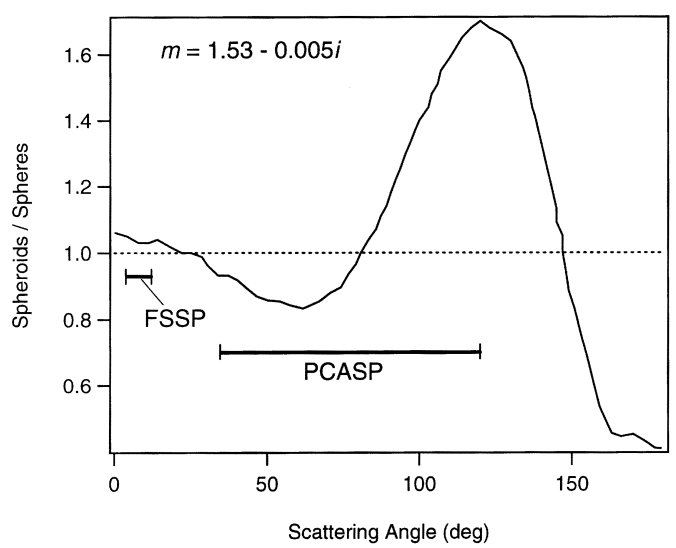

Fig. 2. Ratio of nonspherical to spherical phase functions published by Mishchenko et al. (1997). These data correspond to a distribution of particles thought to be representative of mineral dust aerosols. Also shown are the collection angles for both the PCASP and the FSSP. which receives light scattered between 35 and $120^{\circ}$, results in a partial cancellation of these opposing discrepancies. The effective particle sizes corresponding to each of the bins as described above are found to vary typically by less than $5 \%$ from those calculated using Mie theory.

2.1.3. FSSP. Mounted on the wing opposite to the PCASP was a PMS forward scattering spectrometer probe (FSSP-100). The FSSP, which makes use of an external laser/detector, causes only minimal perturbation of particles or droplets of $20 \mu \mathrm{m}$ diameter or more. Since the Pelican did not sample in-cloud properties for any extended period of time, the size range measured with the FSSP during ACE-2 differed from that more commonly measured for cloud droplet sizing, and instead particles ranging from 0.5 to $8.0 \mu \mathrm{m}$ were binned in 16 diameter intervals. However, measurement of the scattered intensity in the near forward direction, as with the FSSP, results in significant oscillations superimposed on the general increase in intensity with particle size in the range used, as can be seen in Fig. 3. As with the PCASP, particle refractive index influences the measurement, but the lack of a unique particle size corresponding to certain values of scattered intensity prohibits generation of meaningful effective calibrations as described in the previous section. Rather than using all 16 intervals, 3 composite bins were chosen that have little overlap in the corresponding theoretical scattering intensity. These bins have nominal particle diameter ranges of 0.5 to $3.0 \mu \mathrm{m}, 3.0$ to $4.5 \mu \mathrm{m}$, and 4.5 to $8.0 \mu \mathrm{m}$. Similar to the PCASP, the sizing ability of the FSSP is expected to be largely unaffected by nonspherical particles, but unlike the PCASP, this is not due to offsetting

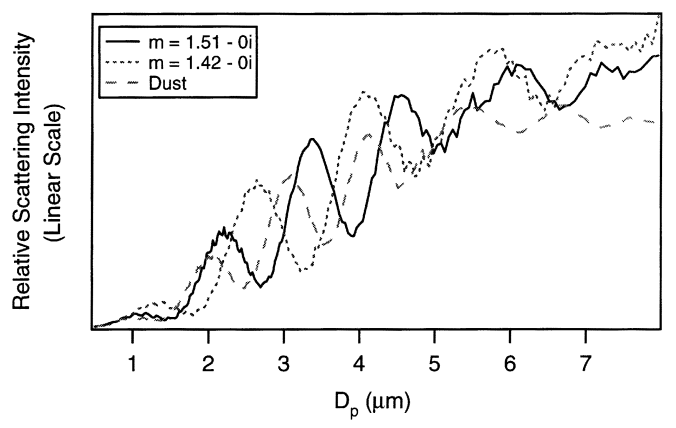

Fig. 3. Collected scattered light intensity as a function of particle size and index of refraction for the FSSP. 
errors, but rather is a result of the weak influence of particle shape on the near forward ( 4 to $12^{\circ}$ ) scattering measured as shown in Fig. 2.

The FSSP was only operational during the first 9 flights. For later missions, size distributions measured by the PCASP were extrapolated to account for scattering and absorption by particles larger than the 3 to $5 \mu \mathrm{m}$ limit (depending on the refractive index) of the PCASP. Boundary layer extrapolations were based on trends observed while the FSSP was operational, whereas extrapolation in the dust layers encountered were based on FSSP measurements made on board the Merlin aircraft (Brenguier, 2000). Fits used for both of the extrapolations are shown in Fig. 4. The expected error from these extrapolations will be discussed in the individual case studies.

\subsection{Integration of sizing measurements}

Combining the three aerosol-size distribution measurements into a consistent data set requires knowledge of the influence of the sampling process on each particle prior to detection. Typically, the most significant effect is the potential growth or evaporation of a hygroscopic particle. No significant heating is expected to be associated with the FSSP, and therefore, the sampled particles are thought to be at equilibrium at ambient relative humidity. The sample stream reaching the DMA was, in general, several degrees Celsius above ambient, resulting in a reduced relative humidity, and consequently, partial evaporation of some particles. However, the degree of evaporation could be predicted since relative humidity was measured at the exit of the DMA. During the ACE-2 experiment, the PCASP de-icing heaters remained off to allow sampling of an aerosol more closely resembling that present at ambient conditions. Without the heaters, assessing the degree to which particles evaporate within the PCASP is more complicated as no direct measurement of humidity is made, and kinetic limitations on evaporation may be important. Upon entering the inlet of the PCASP, the sampled air is heated by approximately $1.5^{\circ} \mathrm{C}$ due to the ram-heating associated with a decelerating flow, although a fraction of this ram heating is potentially offset by the subsequent acceleration of the gas as it enters the sampling cavity. Additionally, the sheath air that is used to focus the sample within the view volume is heated since it is largely recirculated and passes through a pump during each loop. This warm sheath air initially surrounds the intake tube and may therefore transfer heat to the sample indirectly by heating the tubing walls. Sheath and sample flows then join and are accelerated through a nozzle into the sample chamber during which time the intimate contact between the 2 air streams may lead to further heating. Biswas et al. (1987) analyzed this effect in a Royco 226 OPC, which has a flow system very similar to that of the PCASP, and found that the sheath air was heated by 2 to $3^{\circ} \mathrm{C}$. The time the sample stream spends (a)

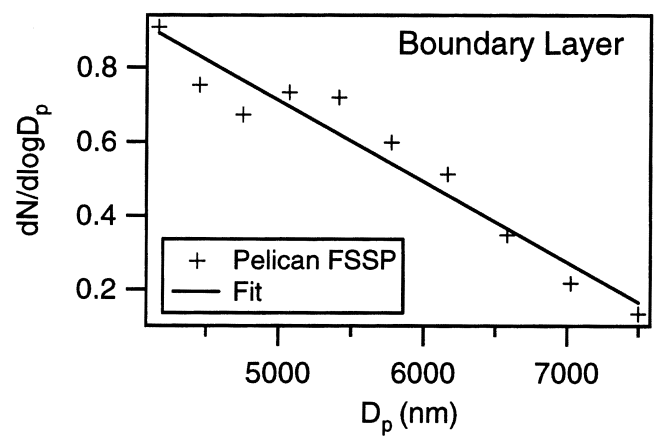

(b)

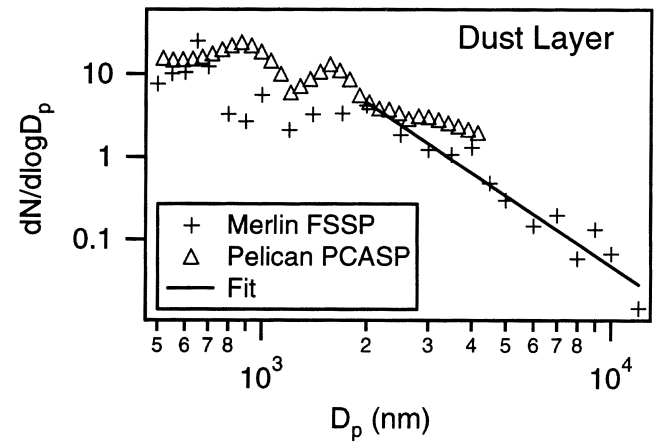

Fig. 4. Extrapolations used during ACE-2 when no FSSP data were available. The extrapolation used for boundarylayer measurements (a) was based on measurements made on the Pelican during similar conditions. That for the dust layers (b) was based on data obtained on board the Merlin (Brenguier et al., 2000) while measuring the same dust event as the Pelican. 
in direct contact with the sheath air may be insufficient to allow larger particles to come to equilibrium under the new conditions. Therefore, in order for larger particles to equilibrate at the relative humidity associated with the heated sheath air, the discussed transfer of heat across the intake tubing walls would be necessary. While these uncertainties related to the heating within the PCASP have not been fully resolved, a combined ram effect and sheath air heating of $3.5^{\circ} \mathrm{C}$ was assumed. The sensitivity of calculated optical properties of the aerosol to this assumption is discussed in the results.

Adjusting for these relative humidity differences requires knowledge of the behavior of the sampled particles, which, in turn, generally necessitates an understanding of the chemical make-up of the individual particles, information not often available at the same temporal and size resolution as the size measurements, as is the case here. Therefore, for each flight, size-dependent aerosol composition for the boundary layer and free troposphere was assumed using available measurements. These chemical compositions also allow for determination of the hygroscopic and optical properties needed for comparisons with the various optical measurements. As part of the ACE-2 study, aerosol chemical composition measurements were made at several land-based locations, including two sites in particular on Tenerife: Punta Del Hidalgo (PDH) located at the Northern end of the island at an elevation of $30 \mathrm{~m}$, and Izaña (IZO) located at $2360 \mathrm{~m}$ along a ridge in the central region of the island. The prevailing lowlevel winds in this region of the Atlantic generally come from the north and therefore PDH served as the first area of the island arriving air masses encountered and thus provided details of the undisturbed marine boundary layer. IZO often experienced upslope winds throughout the day, while measurements made during the night were thought to be characteristic of the undisturbed free troposphere. Particulate chemical species measured at both of these locations included $\mathrm{NH}_{4}^{+}, \mathrm{SO}_{4}^{2-}, \mathrm{Na}^{+}, \mathrm{Cl}^{-}$, and both elemental (commonly referred to as black) and organic carbon (Putaud et al., 2000). A distinction between fine and coarse mode aerosols was made using nominal particle cut diameters of $1 \mu \mathrm{m}$ and $2 \mu \mathrm{m}$ for the PDH and IZO samples, respectively.

Using these data, size-resolved chemical com- positions were then generated corresponding to the boundary layer and free troposphere for each flight. This was accomplished through the use of assumptions relating the concentrations of the various components, while also requiring that the fine and coarse mass fractions calculated using these assumed compositions, in conjunction with the measured size distributions, agreed with the actual measurements made at PDH and IZO. Compositions for the free-tropospheric aerosol during Saharan dust episodes were based in part on the measurements made at IZO, but it was assumed that the majority of the supermicrometer mass resulted from dust particles. This assumption was necessary as the filter and impactor analyses performed did not account for the total mass associated with the dust. The assumed degree of neutralization of the sulfates $\left(\mathrm{H}_{2} \mathrm{SO}_{4}, \mathrm{NH}_{4} \mathrm{HSO}_{4}\right.$, or $\left.\left(\mathrm{NH}_{4}\right)_{2} \mathrm{SO}_{4}\right)$ was based largely on the trends observed in the ratio of ammonium to sulfate relative to particle size. The similar hygroscopic properties of each of these compounds limits the error in growth/evaporation calculations associated with an inaccurate assumption. Examples of aerosol chemical compositions are presented for each of the 4 case studies described below. Filter measurements were also made on board the Pelican during ACE-2 (Schmeling et al., 2000). However, since these samples were not sizeresolved, and often combined the contributions from the free troposphere and boundary layer, they did not provide the necessary information for size-resolved compositions.

External mixtures of sea salt and sulfate particles were assumed to enable the use of published single salt solution thermodynamics data for particle growth/evaporation calculations. While this assumption may lead to some error if there is substantial internal mixing of sea salt and sulfates, it has been shown by Tang (1996) that the degree of mixing leads to insignificant differences in hygroscopic or optical properties of common sulfates and nitrates. Dust particles were also assumed to be mixed externally, which is supported in part by TDMA data taken on Tenerife during ACE-2, which consistently showed hygroscopic and non-hygroscopic fractions with little or no overlap (Swietlicki et al., 2000). Organic and elemental carbon were assumed to be predominantly internally mixed with the sulfates, although a specified fraction was also considered 
to be internally mixed with the sea salt, and the remainder externally mixed. That elemental carbon is expected to be internally mixed with the salt particles is supported by volatility measurements made under similar conditions in the North Atlantic, which showed evidence of a non-volatile residual that was present in the majority of particles and that was composed partially or entirely of elemental carbon (Clarke et al., 1996). No similar evidence is available regarding the mixing state of particulate organic carbon, but it is thought that it is emitted largely from land sources (Cachier et al., 1986) and therefore has had a considerable amount of time en route to accumulate salt species through coagulation and condensation. All internally mixed particles were considered to be homogeneous, an assumption that most likely does not result in substantial errors in optical calculations, as is discussed below.

Given the assumed aerosol composition, the response of a size distribution to changes in relative humidity can be deduced. The hygroscopic behavior of each of the salts considered can be predicted by the following relationship that combines solute and Kelvin terms,

$\frac{\mathrm{RH}}{\gamma_{\mathrm{w}} x_{\mathrm{w}}}=\exp \left(\frac{4 \sigma_{\mathrm{s}} M \mathrm{~W}_{\mathrm{w}}}{R T \rho_{\mathrm{s}} D_{\mathrm{p}}}\right)$

where $\mathrm{RH}$ is the relative humidity, $\gamma_{\mathrm{w}}$ the activity coefficient of the water, $x_{\mathrm{w}}$ the mole fraction of water, $\sigma_{\mathrm{s}}$ the surface tension of the solution, $\mathrm{MW}_{\mathrm{w}}$ the molecular weight of water, $R$ the ideal gas constant, $T$ the temperature, $\rho_{\mathrm{s}}$ the solution density, and $D_{\mathrm{p}}$ the particle diameter. Data obtained through the use of an electrodynamic balance have provided empirical relationships describing the activity and density of concentrated, and even supersaturated, aqueous mixtures of common salts (Tang and Munkelwitz, 1994; Tang, 1996) as well as actual sea salt (Tang et al., 1997). Surface tension increases roughly linearly with increasing solute concentration (Pruppacher and Klett, 1997). An iterative algorithm can then be implemented to determine the size change a particle of known composition undergoes resulting from variations in relative humidity. For aqueous particles present at relative humidities between the crystallization and deliquescence humidities for the particular salt, a supersaturated solution is assumed. In essence, this is equivalent to assuming all particles above their crystallization point have previously deliquesced. The observed relative humidity within the boundary layer during the study had a mean and standard deviation of $78 \pm 7 \%$, which is sufficient for deliquescence for most of the salts considered. For periods during which the humidity was slightly lower than the deliquescence point of a given salt species, this assumption may result in some error, although many of the particles are still likely to have been previously exposed to sufficiently high humidities. The corresponding mean and standard deviation of the relative humidity in the free troposphere was $18 \pm 10 \%$, which is below the crystallization point for most of the salts considered and would result in minimal growth even for the noncrystallized aerosols. Dust, elemental carbon, and organic carbon were assumed to be non-hygroscopic, and, if internally mixed, were only considered to affect the Kelvin term in eq. (1). While mineral dust and elemental carbon are expected to be primarily hydrophobic, this assumption is known not to hold for some organic species likely to be present (Saxena et al., 1995). Although there are little direct data supporting or disputing this approximation, it is indirectly supported by the inverse, though weak, relationship between the organic mass fraction measured at PDH and the average TDMA analyzed growth factor of the hygroscopic fraction during the same time period.

Given the assumed or measured relative humidity within each of the sizing instruments, the evaporation/growth adjustments described above can be made to the corresponding data to determine the complete aerosol-size distribution expected to be present at ambient conditions. For the typical $15-20 \%$ decrease in relative humidity associated with the PCASP, the relative magnitude of this adjustment for an aqueous ammonium sulfate particle ranges from approximately 10 to $25 \%$ corresponding, respectively, to an ambient humidity range of 70 to $90 \%$. For particle size ranges over which the DMA and PCASP data overlapped, the two measurements were simply averaged. The consistent agreement between the PCASP and the FSSP at approximately $2.5 \mu \mathrm{m}$ was used as a cutoff point, below which the PCASP data were assumed to be more accurate, and above which the FSSP data (when 
available) were used. To allow simple averaging and comparison of data, all of the size distributions were interpolated onto a fixed set of logarithmically spaced diameters. Generally, agreement in the number concentration measured by the DMA and the PCASP was within 10 to $20 \%$ in the overlapping region. For measurements within the boundary layer, discrepancies between the concentrations recovered by the PCASP and those recovered by the FSSP were usually less than $30 \%$ in the overlapping range, whereas for measurements made in the free troposphere the corresponding discrepancies occasionally exceeded a factor of 2 , at least in part due to poor counting statistics. Fig. 5 shows the agreement between the size distributions from the three instruments during the flight on 21 June. Among the platform intercomparisons performed during ACE-2, those with the land site at PDH and with the C-130 were of particular interest for the size distribution measurements, as similar data were taken on each platform. Fig. 6 shows the results of these intercomparisons conducted on 14 July. For direct comparison with the low humidity measurement at $\mathrm{PDH}$, the Pelican

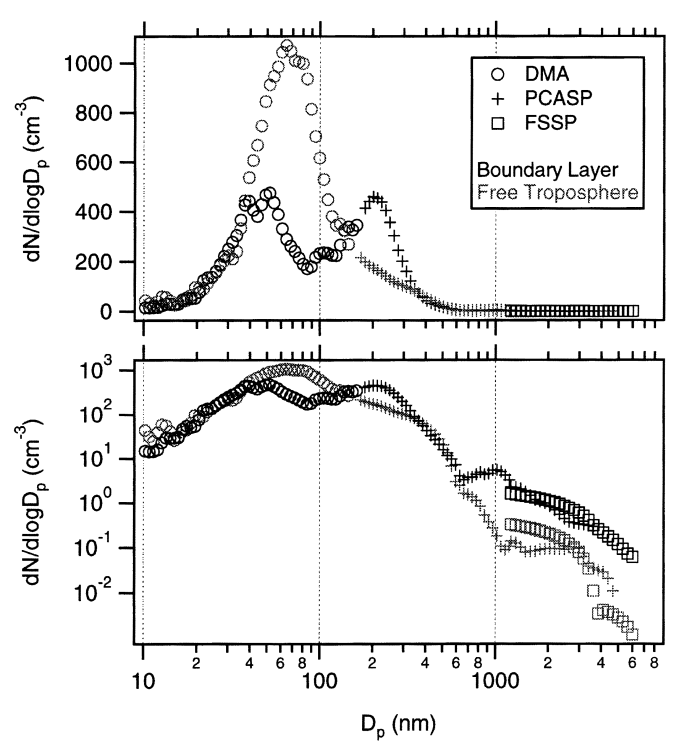

Fig. 5. Comparison of the recovered size distributions from the DMA, PCASP, and FSSP both in the boundary layer and the free troposphere during ACE-2. Each of the distributions was either measured at, or adjusted to, ambient relative humidity. distribution was theoretically dried. While some discrepancies are seen to exist between the measurements made, they are thought to be within experimental error and could potentially be explained by the sampling of slightly different air parcels even when in close proximity.

\subsection{Particle index of refraction}

For accurate evaluation of optical particle measurements, as well as for eventual comparisons with the direct optical measurements made on board the aircraft, knowledge of particle index of refraction is necessary. Subsequent to calculating the wet particle size of a salt particle, and therefore the solute concentration, refractive index can be determined in a straightforward manner through the use of the partial molal refraction approach described by Moelwyn-Hughes (1961). Elemental carbon was assumed to have a constant refractive index of 1.96-0.66i (Seinfeld and Pandis, 1998), while a value of $1.55-0 i$ was used for organic carbon (Larson et al., 1988). The index of refraction of dust particles was based on the previous analysis of samples taken on Tenerife by Patterson et al. (1977), which indicated a relatively constant real component of 1.56 along with an imaginary component inversely related to the wavelength of the incident light. An approximate fit of these data over the visible spectrum yields an imaginary component of $0.17 \times \times 10^{-0.0025 \lambda}$ where $\lambda$ is the incident wavelength in nm. For internal mixtures of elemental and organic carbon with salts, the effective index of refraction was assumed to be the volume-weighted refractive indices of the individual components. Were the particles internally homogeneous, this assumption would be reasonably accurate, but particularly for elemental carbon, this assumption is physically unlikely. However, modeling results by Ackerman and Toon (1981) demonstrate that while the single scatter albedo and scattering phase function of homogeneous and inhomogeneous (modeled as concentric shells) sulfate/elemental carbon particles do differ, for the elemental carbon concentrations observed during ACE-2, these differences are unlikely to result in significant errors.

\subsection{Optical measurements}

While the Pelican payload provided measurement of a wide range of aerosol characteristics, 
because of the goal of achieving radiative closure, the optical parameters of the aerosol were characterized more comprehensively than any other single property. Among the instrumentation used to accomplish this was a 14-wavelength sunphotometer and 3 nephelometers.

2.4.1. NASA sunphotometer. The 14-wavelength NASA Ames airborne tracking sunphotometer continuously measured the optical depth of the column of air between the aircraft and the top of the atmosphere (Schmid et al., 2000). By subtracting from this value the optical depth due to Rayleigh scattering by gas molecules and absorption by certain gas species, the aerosol optical depth for wavelengths between 380 and $1558 \mathrm{~nm}$ was deduced as a function of altitude. The derivative of a continuous measurement of optical depth made during an ascent or descent produces the altitude-dependent extinction coefficient, $\sigma_{\text {ext }}\left(\mathrm{m}^{-1}\right)$,

$\sigma_{\text {ext }}=\frac{\mathrm{d} \tau(z)}{\mathrm{d} z}$

where $\tau(z)$ is the sunphotometer measured optical depth between the instrument's altitude, $z$, and the top of the atmosphere.

For comparison with the sunphotometer data, aerosol-size distributions, adjusted to ambient relative humidity, were used in conjunction with the size-resolved chemical compositions as inputs into Mie theory, from which the extinction coefficient was calculated by summing the integrated extinction coefficients resulting over the range of chemical compositions,

$$
\begin{aligned}
\sigma_{\mathrm{ext}} & =\sum_{i=1}^{k} \int_{D_{\mathrm{p} 1}}^{D_{\mathrm{p} 2}} \frac{\pi}{4} D_{\mathrm{p}}^{2} \\
& \times Q_{\mathrm{ext}}\left(D_{\mathrm{p}}, \lambda, m\left(D_{\mathrm{p}}, i, \mathrm{RH}\right)\right) n\left(D_{\mathrm{p}}, i, z\right) d \log D_{\mathrm{p}},
\end{aligned}
$$

where $i$ represents the particular composition (i.e., $\mathrm{NH}_{4} \mathrm{HSO}_{4}, \mathrm{NaCl}$, etc.), $k$ is the number of separate composition types considered, $D_{\mathrm{p}}$ is the particle diameter over which the integral is performed, $D_{\mathrm{p} 1}$ and $D_{\mathrm{p} 2}$ are the minimum and maximum diameters measured, respectively, which would ideally be 0 and $\infty, Q_{\text {ext }}$ is the particle extinction efficiency, $\lambda$ is the wavelength of the incident light, $m\left(D_{\mathrm{p}}, i, \mathrm{RH}\right)$ is the complex index of refraction of the particle, which is a function of the particle's size, composition, and the ambient relative humid- ity, $\mathrm{RH}$, and $n\left(D_{\mathrm{p}}, i, z\right)$ is the size distribution function of species $i$.

While the above calculations were performed for each of the 14 wavelengths measured by the sunphotometer, detailed comparisons were made for 3 wavelengths $(448,525$, and $667 \mathrm{~nm})$ that are not significantly affected by gas phase absorption, and for which assumptions concerning the refractive indices used were most relevant. The optical parameters calculated are obviously sensitive to the accuracy with which the chemical make-up of the aerosol is estimated, and also to the assumptions concerning particle shape, particularly within the mineral dust layers. Sensitivity to particle shape is somewhat reduced because of the fact that, unlike the relatively large discrepancies present between the phase functions of spherical and nonspherical particles, the error in corresponding extinction cross-sections is expected to have a maximum of $15 \%$, and a more likely value of about $5 \%$, for the particular dust aerosols sampled (Mishchenko et al., 1997). The potential error resulting from the size distribution extrapolations will be discussed subsequently.

2.4.2. Nephelometers. Three separate integrating nephelometers were utilized on the Pelican; a TSI 3563 3-color nephelometer capable of measuring both total scattering and hemispherical backscattering, and two Radiance Research nephelometers operated at different relative humidities, collectively referred to as a passive humidigraph. The sample stream reaching the TSI nephelometer typically had a relative humidity below 40\% within the boundary layer. Detailed results obtained with the TSI and humidigraph nephelometers are described in Öström and Noone (2000) and Gassó et al. (2000), respectively. Located in the nose area of the plane, all three of the instruments sampled from the community inlet downstream of the cyclone. An ideal nephelometer makes use of a Lambertian light source to measure directly the scattering coefficient of an aerosol population, whereas actual nephelometers suffer from non-ideal light sources and an inability to detect light scattered by particles in the near forward or near backward direction.

Comparison of the derived aerosol optical properties with those measured by the nephelometers requires slightly more analysis than did the calculations performed for comparison with the sunphotometer. First of all, only a subset of the full 

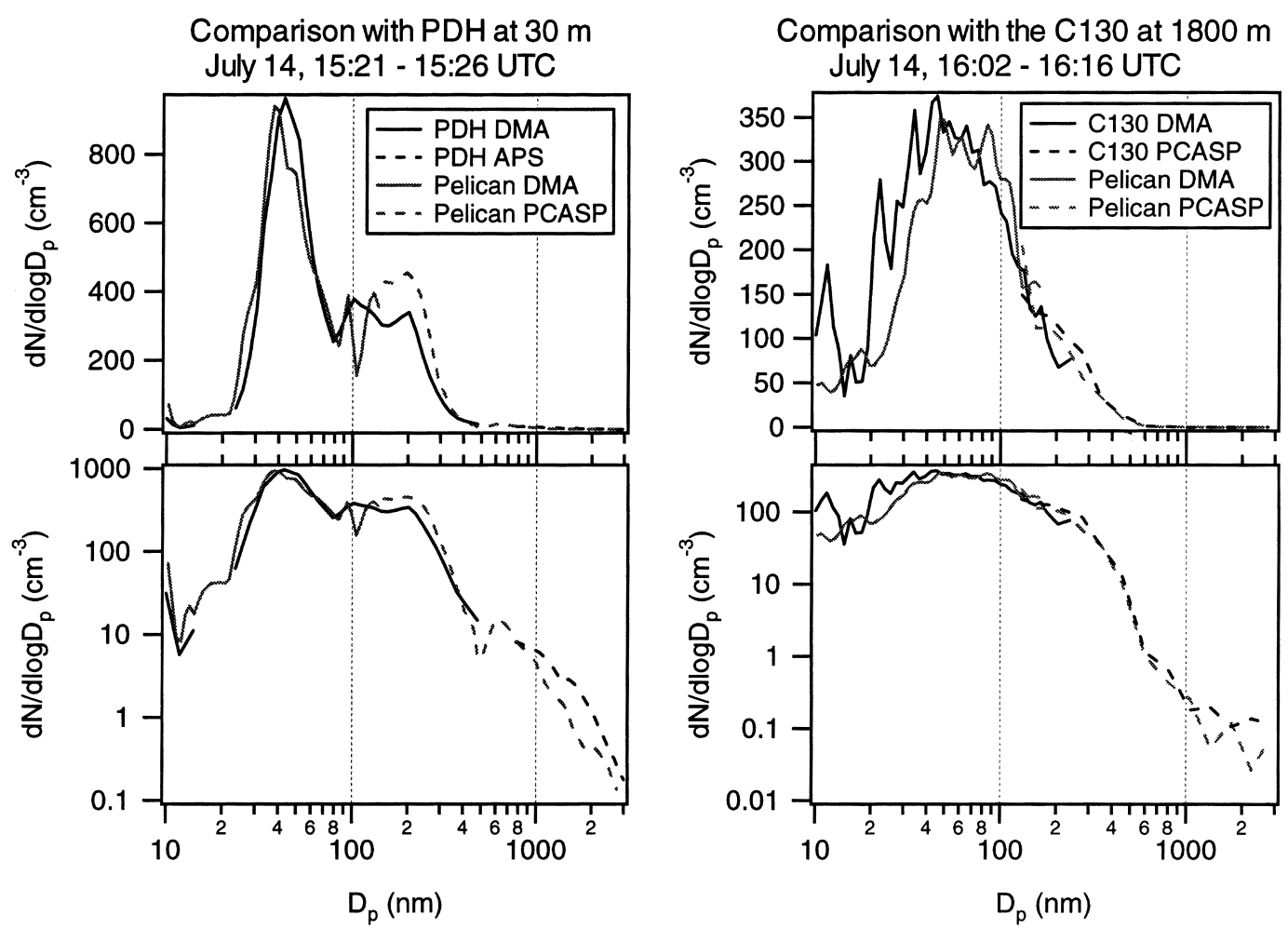

Fig. 6. Results of size distribution intercomparisons performed with a land site (PDH) and another aircraft (C-130) during ACE-2. The distribution measured at PDH incorporated data from both a DMA (R. Van Dingenen, personal communication, 1998) and an Aerodynamic Particle Sizer (E. Swietlicki, personal communication, 1998), while that on the C-130 combined data from a DMA (C. O'Dowd, personal communication, 1998) and PCASP (Johnson et al., 2000). Pelican size distributions were theoretically dried for comparison with the PDH data, while the measurements made during the C-130 intercomparison were of the dried aerosol.

spectrum of particles will reach the nephelometers because of losses within the cyclone. While the cyclone has a nominal $50 \%$ cut size of $2.5 \mu \mathrm{m}$ diameter for a unit density particle at STP, consideration of the particle density and gas viscosity is necessary to predict accurately which particles are removed. Although the change in cut size may be relatively insignificant for aqueous particles in the boundary layer, for dust particles that have densities on the order of $2.6 \mathrm{~g} \mathrm{~cm}^{-3}$ (Tegen and Fung, 1994), the cutoff will be reduced by about $40 \%$. Penetration efficiency as a function of particle diameter was then determined using an s-curve relationship appropriate for the cyclone. For those particles that do penetrate the cyclone, theoretical growth/evaporation calculations are used to predict the equilibrium size of the particle at the relative humidities measured within each of the nephelometers. Frequently, the humidity of the gas stream entering the humidigraph is below the crystallization point of certain salt compounds. When this occurs, only if the humidity in the humidified nephelometer is above the deliquescence point for the given salt is an aqueous solution assumed.

Anderson et al. (1996) investigated the nonidealities in the light source as well as the truncation of near forward and near backward scattered light for the TSI 3563 for measurement of both total scattering and hemispherical backscattering. No similar data are available for the Radiance Research nephelometers, so their characteristics were assumed to be equivalent to those of the TSI instrument. The resulting angular sensitivity can be utilized to determine the expected scattering intensity as measured by the nephelometer, 


$$
\begin{aligned}
& \sigma_{\text {sca,neph }}, \\
& \sigma_{\text {sca,neph }}=\sum_{i=1}^{k} \int_{D_{\mathrm{p} 1}}^{D_{\mathrm{p} 2}} \eta\left(D_{\mathrm{p}}, \rho(i, \mathrm{RH}), \mu\right) \frac{\pi}{4} D_{\mathrm{p}}^{2} \\
& \times Q_{\text {sim }}\left(D_{\mathrm{p}}, \lambda, m\left(D_{\mathrm{p}}, i, \mathrm{RH}\right), f(\Theta)\right) \\
& \times n\left(D_{\mathrm{p}}, i, z\right) d \log D_{\mathrm{p}},
\end{aligned}
$$

where $\eta\left(D_{\mathrm{p}}, \rho(i, \mathrm{RH}), \mu\right)$ is the penetration efficiency through the cyclone and associated tubing for a particle of a given size and density contained within a gas with viscosity, $\mu$, and $Q_{\text {sim }}$ is the expected scattering efficiency for a nephelometer with angular sensitivity, $f(\Theta)$ (Anderson et al., 1996).

\section{Results and discussion}

During the 6-week period of intensive sampling associated with ACE-2, the Pelican flew 21 missions ranging in duration from just over $2 \mathrm{~h}$ to more than $10 \mathrm{~h}$. The diverse payload on board the Pelican allowed for participation in the coordinated CLEARCOLUMN, CLOUDYCOLUMN, and LAGRANGIAN experiments. The large volume of size distribution data recorded during ACE-2 precludes description of the findings of each of the separate flights. Instead, an attempt is made to categorize the measured aerosols into groups with similar characteristics and, in general, similar origins. An in-depth analysis of 4 of the flights is given here with the goal of evaluating radiative closure.

The first mission flown by the Pelican during ACE-2 was on 18 June 1997. It was not until the 12th flight on 7 July, however, that an air mass arrived in the area of study that clearly possessed characteristics suggesting significant influences from non-marine sources. Prior to 7 July, and occasionally at later dates, back trajectories as calculated by the Royal Netherlands Meteorological Institute (KNMI) using the European Centre for Medium Range Weather Forecasts (ECMWF) model suggested that both the boundary-layer and free-tropospheric air had spent several days over the North Atlantic. This length of time is generally sufficient to reduce substantially any influence from previous land-based emissions of aerosols or their precursors. Following this initial period, during which only relatively clean air masses were encountered, the calculated back trajectories typically showed air parcels arriving in the local boundary layer had either passed over the Iberian Peninsula, or just adjacent to it. As a result, relatively small changes in the path taken by an air mass arriving in the ACE- 2 area could have significant impacts on the properties of the sampled aerosol. At approximately the date the boundary-layer trajectories shifted towards Europe, the source region of the free-tropospheric aerosols switched from the Atlantic to Northern Africa. On multiple occasions, these air parcels arriving from Africa contained substantial quantities of Saharan dust particles.

\subsection{Overall aerosol properties}

\subsubsection{Boundary layer}

3.1.1.1. Background marine. Consistent with previous measurements made during relatively clean conditions in the Northeastern Atlantic, submicrometer number size distributions were found to be bimodal in nature, possessing distinct nuclei and accumulation modes (Jensen et al., 1996; Russell et al., 1996a; Raes et al., 1997). The nuclei mode, which is thought to form as a result of particle nucleation followed by growth due to condensation and coagulation, peaked at around $60 \mathrm{~nm}$. While this peak size was found on occasion to be as low as approximately $30 \mathrm{~nm}$, no appreciable concentration of even smaller particles representative of recent nucleation events were observed within the boundary layer. Although the absence of recently formed particles in the marine boundary layer is not unusual for this region, the limited counting statistics associated with detecting these particles with a rapidly scanning DMA may result in an inability to accurately measure relatively small concentrations of these ultrafine aerosols. Subsequent processing of the particles within the nuclei mode, particularly within clouds (Hoppel et al., 1986), serves to form the accumulation mode. While the majority of particles were smaller than $1 \mu \mathrm{m}$, most of the aerosol mass within the clean boundary layer always resided in particles $>1 \mu \mathrm{m}$ that are presumably composed of sea salt.

Mie theory calculations were performed using the recovered size distributions and assumed compositions to evaluate the relative importance of the fine and coarse mode fractions to the optical 
properties of the aerosol. Although there is nothing intrinsically special about the $1 \mu \mathrm{m}$ division, it does offer, roughly, a distinction between the sulfates and carbon particles that are thought to be largely present in the fine mode, and the sea salt, and possibly dust particles, composing most of the coarse mode. On average, for these clean boundary-layer aerosols, the submicron and supermicron particles were found to contribute approximately equally both to the total aerosol extinction coefficient and to the total aerosol hemispherical backscattering coefficient, a quantity slightly more indicative of the radiative forcing resulting from an aerosol population.

While the bimodal number distribution and supermicron mass mode were present in all of the distributions measured, large variations existed in the properties of each of these modes as well as in the distribution as a whole. This is clearly shown in Table 1, which presents the mean and range of a number of key parameters describing the clean boundary layer as well as the other aerosol types described in more detail below. Since the primary focus of this paper is radiative closure using in situ measurements, the particle size distribution either measured at, or theoretically adjusted to, ambient relative humidity is most relevant. Each of the quantities listed in Table 1 was, therefore, calculated with respect to the ambient distributions.

3.1.1.2. Polluted boundary layer. During periods for which the air masses arriving in the boundarylayer crossed sections of Western Europe, total number concentrations increased to over $1000 \mathrm{~cm}^{-3}$, and for the most polluted case, exceeded $4000 \mathrm{~cm}^{-3}$. In addition to the enhanced number concentrations of these continentally influenced aerosols, the intensive properties of the associated size distributions changed as well. The most obvious difference in the number distribution associated with the polluted aerosols relative to those measured during background conditions is the lessening importance of the nuclei mode relative to the accumulation mode. Of the 4 flights during which these enhanced number concentrations were measured, the size distributions corre-

Table 1. Average and range of parameters describing the aerosol types sampled during ACE-2

\begin{tabular}{cccccc}
\hline & Clean BL & Polluted BL & Clean FT & Polluted FT & Dust FT \\
\hline No. of cases & 10 & 4 & 8 & 1 & 3 \\
$N_{\text {total }}\left(\mathrm{cm}^{-3}\right)$ & $492(288-720)$ & $2350(1050-4110)$ & $363(240-434)$ & 692 & $281(272-290)$ \\
$D_{\mathrm{p}}^{\text {num }}(\mathrm{nm})$ & $123(32-224)$ & $170(142-193)$ & $63(50-73)$ & 91 & $83(78-89)$ \\
$D_{\mathrm{p}}^{\text {SA }}(\mathrm{nm})$ & $818(307-1950)$ & $392(342-441)$ & $136(113-158)$ & 147 & $2310(2030-2600)$ \\
$D_{\mathrm{p}}^{\text {vol }}(\mathrm{nm})$ & $3670(2200-4700)$ & $2890(2000-3940)$ & $1740(890-2950)$ & 895 & $4300(3860-4740)$ \\
$D_{\mathrm{p}}^{\text {nuc }}(\mathrm{nm})$ & $58(27-80)$ & $101(89-112)$ & $64(34-95)$ & 112 & $98(89-106)$ \\
$D_{\mathrm{p}}^{\text {acc }}(\mathrm{nm})$ & $237(225-252)$ & $243(178-317)$ & $\mathrm{NA}$ & $\mathrm{NA}$ & $\mathrm{NA}$ \\
$D_{\mathrm{p}}^{\text {min }}(\mathrm{nm})$ & $130(89-159)$ & $184(178-189)$ & $\mathrm{NA}$ & $\mathrm{NA}$ & $\mathrm{NA}$ \\
$\frac{N_{\text {nuc }}}{N_{\text {acc }}}$ & $1.85(0.55-5.24)$ & $1.51(1.27-1.75)$ & $\mathrm{NA}$ & $\mathrm{NA}$ & NA \\
$\sigma_{\text {ext }}(<1 \mu \mathrm{m})$ & $0.92(0.16-2.18)$ & $2.19(1.32-3.54)$ & $1.85(0.85-2.75)$ & 5.32 & $0.14(0.11-0.16)$ \\
$\sigma_{\text {ext }}(>1 \mu \mathrm{m})$ & & & & & 14.4 \\
$\frac{\sigma_{\text {bsca }}(<1 \mu \mathrm{m})}{\sigma_{\text {bsca }}(>1 \mu \mathrm{m})}$ & $0.98(0.22-2.27)$ & $2.00(1.37-2.91)$ & $3.88(1.92-5.66)$ & & $0.22(0.15-0.29)$ \\
\hline
\end{tabular}

Properties described are the aerosol number concentration, $N_{\text {total }}$, the number median diameter, $D_{\mathrm{p}}^{\text {num }}$, the surface area median diameter, $D_{\mathrm{p}}^{\mathrm{SA}}$, the volume median diameter, $D_{\mathrm{p}}^{\text {vol }}$, the diameter corresponding to the peak in the nuclei mode, $D_{\mathrm{p}}^{\text {nuc }}$, the diameter corresponding to the peak in the accumulation mode, $D_{\mathrm{p}}^{\text {acc }}$, the diameter corresponding to the minimum between the nuclei and accumulation modes, $D_{\mathrm{p}}^{\min }$, the ratio of the number of particles in the nuclei mode to the number in the accumulation mode, $N_{\text {nuc }} / N_{\text {acc }}$, the ratio of the extinction resulting from the submicron aerosol fraction to that resulting from the supermicron aerosols, $\sigma_{\text {ext }}(<1 \mu \mathrm{m}) / \sigma_{\text {ext }}(>1 \mu \mathrm{m})$, and the similar ratio for hemispherical backscattering, $\sigma_{\text {bsca }}(<1 \mu \mathrm{m}) / \sigma_{\text {bsca }}(>1 \mu \mathrm{m})$. Each of the quantities corresponds to size distributions either measured at, or adjusted to, ambient relative humidity.

Tellus 52B (2000), 2 
sponding to the 3 most polluted cases showed little or no nuclei mode. The aerosol measured during the remaining case did have a discrete nuclei mode, although the trough separating it from the accumulation mode was significantly more shallow than observed during the relatively clean cases. Evidence of this shift towards monomodality with increasing continental influence has been observed in the North Atlantic by others (Jensen et al., 1996; Russell et al., 1996). This results from an increase in the aerosol surface area available in the accumulation mode that acts as a sink for condensable species that might otherwise form new particles or add to nuclei mode particles. Although a slight majority of the volume (at ambient RH) still resides in the supermicron aerosol fraction, the submicron fraction was found to contribute an average of about twice as much to both the extinction and backscattering coefficients.

3.1.2. Free troposphere. The distinction between free-tropospheric aerosols that contained significant quantities of mineral dust and those that did not was relatively sharp. During 3 flights in particular, when mineral dust was present aloft, the coarse mode aerosol mass exceeded $10 \mu \mathrm{g} \mathrm{m}^{-3}$, while values of less than $1 \mu \mathrm{g} \mathrm{m}^{-3}$ characterized the non-dusty flights. However, this categorical distinction does not preclude the presence of sufficient dust particles to dominate the total mass of the "non-dusty" aerosol, but rather serves as a simple division between those cases where dust was likely to play a significant role in the total columnar optical depth, and those where it was not.

3.1.2.1. Free troposphere without mineral dust. Back trajectories corresponding to most of the non-dusty cases remained over the North Atlantic for several days, although in 2 instances they passed over sections of Africa. From previous measurements made at IZO, Raes et al. (1997) observed that the aerosol number distribution within the free troposphere during clean conditions consisted of a single, nuclei-sized mode with an integrated number concentration of approximately $425 \mathrm{~cm}^{-3}$ at STP. Size distributions measured on board the Pelican during ACE-2 support these findings. The location of this single mode varied little over the measurement period, although the total number concentration changed by almost a factor of 2 . No clear indication of high concentrations of freshly nucleated particles was observed during any of the flights. A maximum altitude of $3.9 \mathrm{~km}$ was achievable by the Pelican, so nucleation occurring at even higher altitudes was still a possibility. Aerosol properties measured during the 21 June flight were sufficiently different from the remaining cases that they are presented separately in Table 1 . The increased number concentration and median diameter measured during this flight suggest atypical sources or processing of some kind, although the calculated back trajectories suggest that the origin of this air mass was a region of the North Atlantic similar to most of the other clean cases. Similar to the polluted boundary layer, both extinction and backscattering were dominated by submicron particles. However, relative to both the volume and extinction associated with the aerosol within the boundary layer, the contribution from the clean free-tropospheric aerosol is almost negligible.

3.1.2.2. Free troposphere with mineral dust. The free troposphere number distributions for Saharan dust laden aerosols were, in fact, very similar to those corresponding to clean conditions, possessing a single mode consisting of several hundred particles $\mathrm{cm}^{-3}$. Only when aerosol volume or extinction is plotted relative to particle size is the presence of the larger dust particles apparent. As will be discussed in the section describing the case studies, these relatively few particles resulted in extinction coefficients of the same magnitude as those resulting from continentally influenced, boundary-layer aerosols. Although the total aerosol mass in these cases is subject to error due to the extrapolations used, the majority of the associated extinction is seen to result from particles within the PCASP range (at least when the range is adjusted to account for index of refraction). One of the most interesting features of the observed dust layers was the gradient in concentration encountered as a function of altitude. The extinction resulting from mineral dust in the free troposphere was observed to increase by as much as 2 orders of magnitude over as little as a kilometer in altitude change. The sampling site at IZO was located within this gradient, and therefore, slight shifts in the height of the dust layer could have pronounced impacts on the measurements made there. Even larger error could be incurred if lower elevation, ground-based, measurements were used as a basis to estimate the columnar optical properties. 


\subsection{Phase functions}

To offer further insight into the optical characteristics of each of the aerosol types discussed above, as well as to provide potential inputs for remote sensing algorithms, scattering phase functions were calculated. Average phase functions were calculated for the free-tropospheric and boundary-layer aerosol measured during each flight. The mean and standard deviation of the phase functions associated with each of the described aerosol types were then calculated using the appropriate set of flight-average values. The results of these calculations are shown in Fig. 7. The mean and standard deviation were calculated using the logarithm of the flight-average values since the absolute values typically span several orders of magnitude. Additionally, the theoretical results of Mishchenko et al. (1997) were used to predict the phase functions associated with nonspherical dust particles. There is clearly more variation in the phase functions resulting from measurements made within the clean marine boundary layer than from the polluted cases, although this may, in part, be a result of a more limited sample for the polluted aerosols. The relatively shallow phase function calculated for the non-dusty free troposphere is a result of both the high concentration of small particles and the enhanced absorption by these particles due to the higher elemental carbon content assumed (based on measurements). As previously discussed, these particles have little impact on the columnar radiative properties of the aerosol. For the other, optically more important, aerosol types, variability

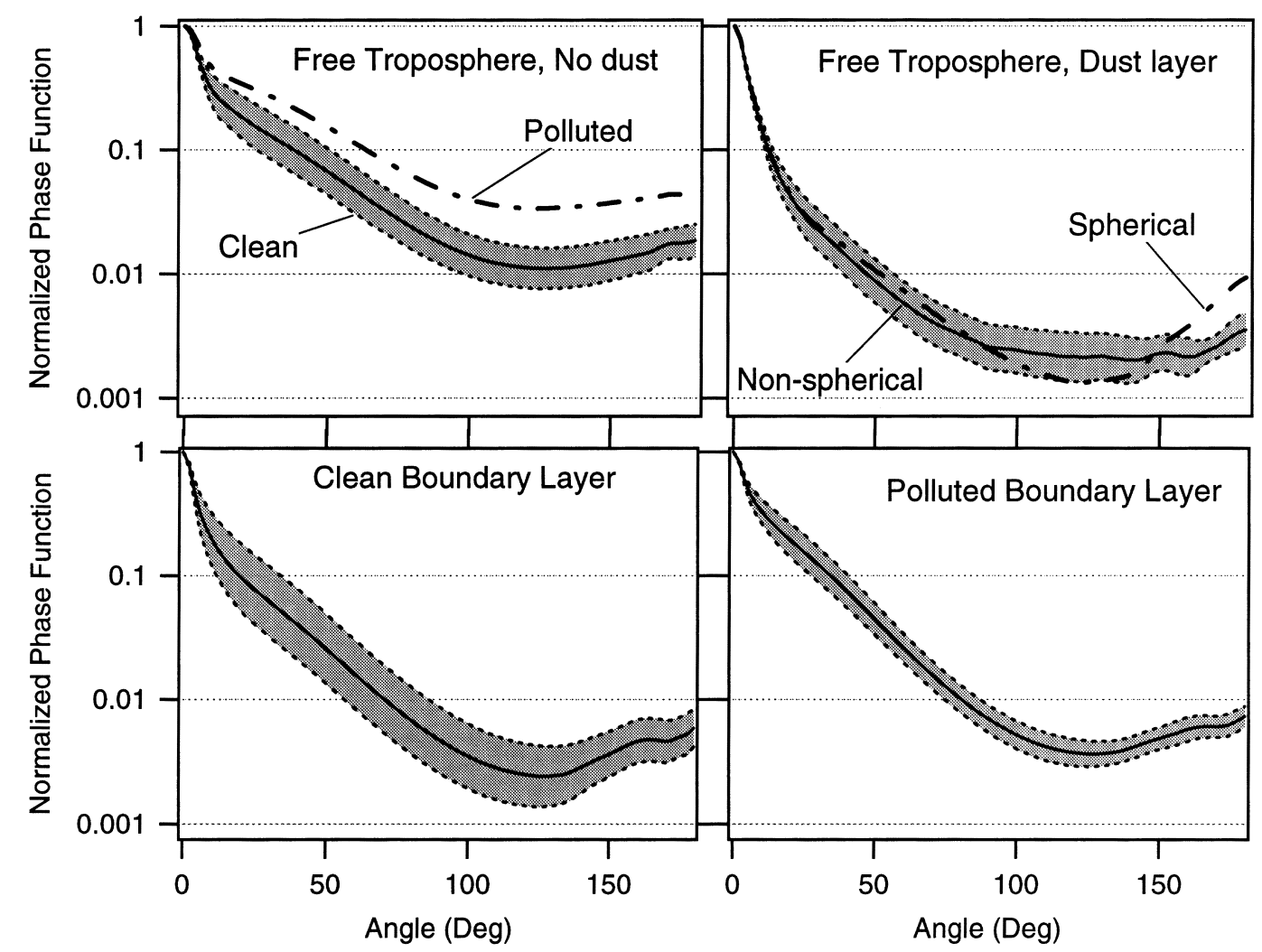

Fig. 7. Averaged phase functions corresponding to each of the aerosol types characteristic of the ACE-2 region. The solid line represents the mean value of the phase functions measured during flights associated with the particular aerosol type, while the shaded area corresponds to \pm 1 standard deviation. Phase functions calculated for the dust aerosols were adjusted to account for the fact that the particles are likely not spheres through the use of modeling results by Mishchenko et al. (1997). All size distributions were adjusted to ambient relative humidity. 
within the categories is seen to be comparable to the variability between the categories, indicating that errors resulting from assuming a constant phase function for a given type of aerosol may be similar in magnitude to assuming an incorrect aerosol type altogether.

\section{Case studies}

While assessment of radiative closure is possible using any type of flight pattern, vertical spirals in a cloudless area are particularly useful in that they allow for a continuous profile of sunphotometerderived extinction coefficients from near sea-level to well into the free troposphere. During ACE-2, vertical spirals were flown on 8 of the 21 Pelican missions, although clouds were present during one of these spirals, compromising the sunphotometer data. Of the 7 remaining flights, 4 were conducted early in the campaign when clean conditions prevailed. Since the focus of this campaign was to characterize Saharan dust and European pollution aerosols, only one of these background flights was chosen, along with each of the non-background cases, for detailed analysis. The primary focus here is a discussion of the comparisons between the derived and measured optical parameters. More detailed analyses of the radiative impact of the aerosols studied is available elsewhere (Schmid et al., 2000; Öström and Noone, 2000; Gassó et al., 2000).

\subsection{Uncertainty analysis}

In an attempt to quantify the effect uncertainties in the measurements made and assumptions used have on radiative closure, a number of sources of error were considered for each of the 4 case studies. This procedure was performed for each of the wavelengths measured by the sunphotometer, and for each of the nephelometers utilized. The individual sources of error considered were uncertainty concerning the degree to which the aerosol was heated in the PCASP; errors in the measurement of the ambient relative humidity as well as that within each of the nephelometers; error in the concentrations used for the size distribution extrapolation when no FSSP data were available; incorrect sizing by the DMA and OPCs; incorrect assumptions about the fraction of the aerosol assumed to be non-hygroscopic (i.e., EC, OC, and dust); incorrect assumptions concerning the mixing state of the aerosol; error related to the assumption that salt aerosols were hydrated when the $\mathrm{RH}$ was above the appropriate crystallization point; error resulting from the assumption that organic carbon aerosol is non-hygroscopic; and uncertainty regarding the penetration efficiency of the cyclone. Additionally, random errors associated with each of the instruments were considered.

The resulting combined uncertainties are presented for each comparison as a function of altitude in the difference plots that are described below in the discussion of the individual case studies. A subset of these data are summarized in Table 2. Many of the uncertainties are highly variable among flights and as a function of altitude, so the averaged values presented in the table provide only a degree of insight into the relative importance of each of the potential sources of error. Several of the responses to the specified perturbations seem counter-intuitive at first. These peculiarities result from the abrupt change in particle size associated with either the crystallization or deliquescence point for the salts considered. For instance, an increase in the ambient relative humidity in the free troposphere is seen to result in a decrease in the calculated extinction coefficient. In this case, the drying associated with the PCASP was originally sufficient to reduce the relative humidity below the crystallization point of at least one of the salts assumed to be present. The calculated size of the particles at ambient $\mathrm{RH}$ is therefore much larger than for the case in which a higher ambient humidity prevents crystallization of the particles within the PCASP. A description of the relative importance of each of the sources of error for each of the instruments under the range of conditions encountered would be prohibitively long. However, it is clear from these results that sizing accuracy, mixing state, degree of heating within the PCASP, and assumptions concerning the hygroscopicity of organics are among the most important sources of error in many of the cases analyzed. Relative to these uncertainties, ultimate determination of scattering or extinction from the size distribution measurements is not particularly sensitive to the extrapolation used in the absence of FSSP data. Random errors associated with each of the measurements often exceeded the uncertainty attributable to the other perturba- 
Table 2. Uncertainties related to radiative closure

\begin{tabular}{|c|c|c|c|c|c|c|c|c|c|}
\hline \multirow{2}{*}{\multicolumn{2}{|c|}{ Perturbation }} & \multicolumn{4}{|c|}{ Sunphotometer $\left(\sigma_{\mathrm{ext}}\right) @ 525 \mathrm{~nm}$} & \multicolumn{4}{|c|}{ Nephelometer $\left(\sigma_{\mathrm{sca}}\right)$ for $\mathrm{RH}_{\text {neph }}<\mathrm{RH}_{\mathrm{amb}}$} \\
\hline & & \multicolumn{2}{|c|}{ boundary layer } & \multicolumn{2}{|c|}{ free troposphere } & \multicolumn{2}{|c|}{ boundary layer } & \multicolumn{2}{|c|}{ free troposphere } \\
\hline Type & Magnitude & clean & polluted & no dust & dust & clean & polluted & no dust & dust \\
\hline PCASP heating & $\pm 2^{\circ} \mathrm{C}$ & $+17.1 /-6.2 \%$ & $+19.8 /-9.0 \%$ & $+0.6 /-0.3 \%$ & $+0.3 /-0.3 \%$ & $+12.3 /-6.8 \%$ & $+12.2 /-8.0 \%$ & $+0.6 /-0.5 \%$ & $+0.6 /-0.5 \%$ \\
\hline RH measurement & $\pm 3 \%$ & $+2.8 /-4.1 \%$ & $+6.5 /-7.2 \%$ & $-0.4 /-3.5 \%$ & $+0.0 /-0.4 \%$ & $+3.7 /-0.1 \%$ & $-0.3 /-3.3 \%$ & $+5.8 /-4.3 \%$ & $-0.5 /-1.2 \%$ \\
\hline FSSP extrapolation & $\pm 50 \%$ & $+4.6 /-3.1 \%$ & $+3.1 /-2.0 \%$ & $+2.1 /-1.4 \%$ & $+12.7 /-8.5 \%$ & $+0.2 /-0.1 \%$ & $+0.1 /-0.1 \%$ & $+0.0 /-0.0 \%$ & $+0.2 / 0.2 \%$ \\
\hline sizing accuracy & $\pm 5 \%$ & $+18.4 /-14.5 \%$ & $+20.8 /-16.0 \%$ & $+18.8 /-15.0 \%$ & $+11.3 /-9.9 \%$ & $+17.7 /-14.4 \%$ & $+18.8 /-15.4 \%$ & $+20.0 /-16.1 \%$ & $+8.8 /-7.6 \%$ \\
\hline carbon, dust fraction & $\pm 50 \%$ & $-4.3 /+3.6 \%$ & $-1.8 /+2.9 \%$ & $+3.7 /-5.8 \%$ & $+0.2 /-1.2 \%$ & $-6.6 /+8.1 \%$ & $-4.5 /+2.8 \%$ & $-2.8 /+0.5 \%$ & $-2.6 /+2.5 \%$ \\
\hline mixing state & external/internal & $+0.8 /-3.8 \%$ & $-4.8 /-0.5 \%$ & $+10.2 / 3.9 \%$ & $-5.6 /-1.9 \%$ & $+24.2 /-17.1 \%$ & $+4.7 /-2.0 \%$ & $+16.6 /-16.7 \%$ & $+10.3 /-17.4 \%$ \\
\hline deliquescence & if $\mathrm{RH}_{\mathrm{amb}}>\mathrm{RH}_{\mathrm{del}}$ & $-1.6 \%$ & $-2.9 \%$ & $+4.3 \%$ & $-3.0 \%$ & $+6.3 \%$ & $+0.4 \%$ & $+13.5 \%$ & $+5.4 \%$ \\
\hline organic hygroscopicity & $\sim \mathrm{NH}_{4} \mathrm{HSO}_{4}$ & $+14.6 \%$ & $+2.8 \%$ & $+14.3 \%$ & $+13.0 \%$ & $+17.7 \%$ & $+5.1 \%$ & $+16.5 \%$ & $-0.2 \%$ \\
\hline cyclone cutoff & $\pm 15 \%$ & $\mathrm{~N} / \mathrm{A}$ & $\mathrm{N} / \mathrm{A}$ & $\mathrm{N} / \mathrm{A}$ & $\mathrm{N} / \mathrm{A}$ & $+2.3 /-5.1 \%$ & $+0.3 /-5.4 \%$ & $+1.6 /-2.2 \%$ & $+8.5 /-9.9 \%$ \\
\hline size distribution random error & $\pm \sqrt{N}$ & $\pm 14.8 \%$ & $\pm 11.5 \%$ & $\pm 23.8 \%$ & $\pm 22.9 \%$ & $\pm 8.9 \%$ & $\pm 5.3 \%$ & $\pm 18.4 \%$ & $\pm 14.7 \%$ \\
\hline nephelometer random error & $6.5 \cdot 10^{-7} \mathrm{~m}^{-1}$ & $\mathrm{~N} / \mathrm{A}$ & $\mathrm{N} / \mathrm{A}$ & $\mathrm{N} / \mathrm{A}$ & $\mathrm{N} / \mathrm{A}$ & $\pm 8.2 \%$ & $\pm 1.4 \%$ & $\pm 61.3 \%$ & $\pm 6.9 \%$ \\
\hline sunphotometer random error & est. from scatter & $\pm 6.7 \%$ & $\pm 6.2 \%$ & $\pm 27.7 \%$ & $\pm 3.6 \%$ & $\mathrm{~N} / \mathrm{A}$ & $\mathrm{N} / \mathrm{A}$ & $\mathrm{N} / \mathrm{A}$ & $\mathrm{N} / \mathrm{A}$ \\
\hline
\end{tabular}

Each quantity represents the average response to the specified perturbation for the 4 case studies discussed. Most of the listed uncertainties are relatively straightforward, although some require further description. In the text, it is stated that salt particles present at a RH above their crystallization point are assumed to have deliquesced. The uncertainty related to this assumption has been estimated by analyzing the data with the assumption that only when the ambient RH is above the deliquescence point of the salt are the particles hydrated. To estimate the potential error resulting from the assumption that the organics particle were non-hygroscopic, they were assumed to have growth characteristics identical to ammonium bisulfate. Estimation of the random error in the humidigraph and TSI nephelometer measurements was accomplished by adjusting the values specified by Gassó et al. (this issue) and Anderson et al. (1996) to the 90s sampling interval employed here. Scatter in the optical depths measured by the sunphotometer was used to estimate the random error associated with the derived extinction coefficients for each flight. The uncertainty related to the FSSP extrapolation is only relevant for those flights in which the FSSP was inoperable. 

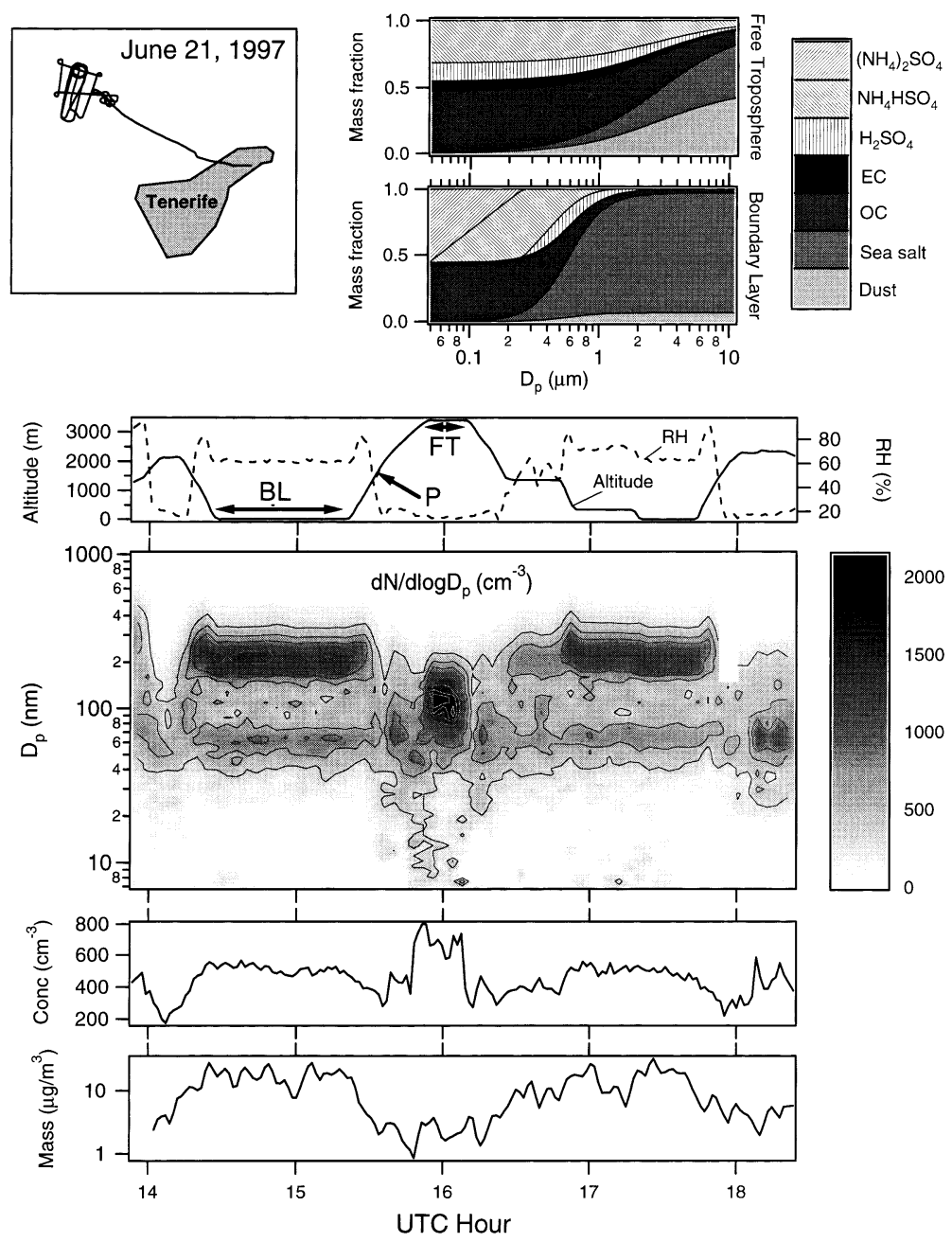

Fig. 8. Size distributions, derived properties, and optical comparisons during a flight that measured an unpolluted boundary layer and a free troposphere with no dust layer. Shown on page 1 are assumed chemical compositions, the flight track, relative humidity and pressure during the flight, an image plot showing the relative change in size distribution as a function of time, and the integrated number concentration and dry aerosol mass. Shown on page 2 are the number, volume, and extinction distributions for the averaging periods indicated on page $1(\mathrm{BL}=$ boundary layer, $\mathrm{FT}=$ free troposphere, and $\mathrm{P}=$ altitude profile), and the comparisons between calculated and measured extinction and scattering coefficients. Associated with each of the comparisons is a difference plot that presents the fractional discrepancy between the calculated and measured property (diamonds) along with the uncertainty bounds (dashed lines) calculated from the perturbations listed in Table 2. To provide greater detail for the majority of the data points, fractional discrepancies $>1$ are presented as arrows, with the actual discrepancy shown in parentheses. With the exception of the dry aerosol mass, all of the data correspond to the aerosol at ambient $\mathrm{RH}$.

tions, although an average value of these estimates is of little use given the variability in the aerosol loading observed even for a given class of conditions.
21 June 1997. KNMI back trajectories terminating at Tenerife on 21 June, show that both the boundary-layer and free-tropospheric air masses had remained over the North Atlantic for several 

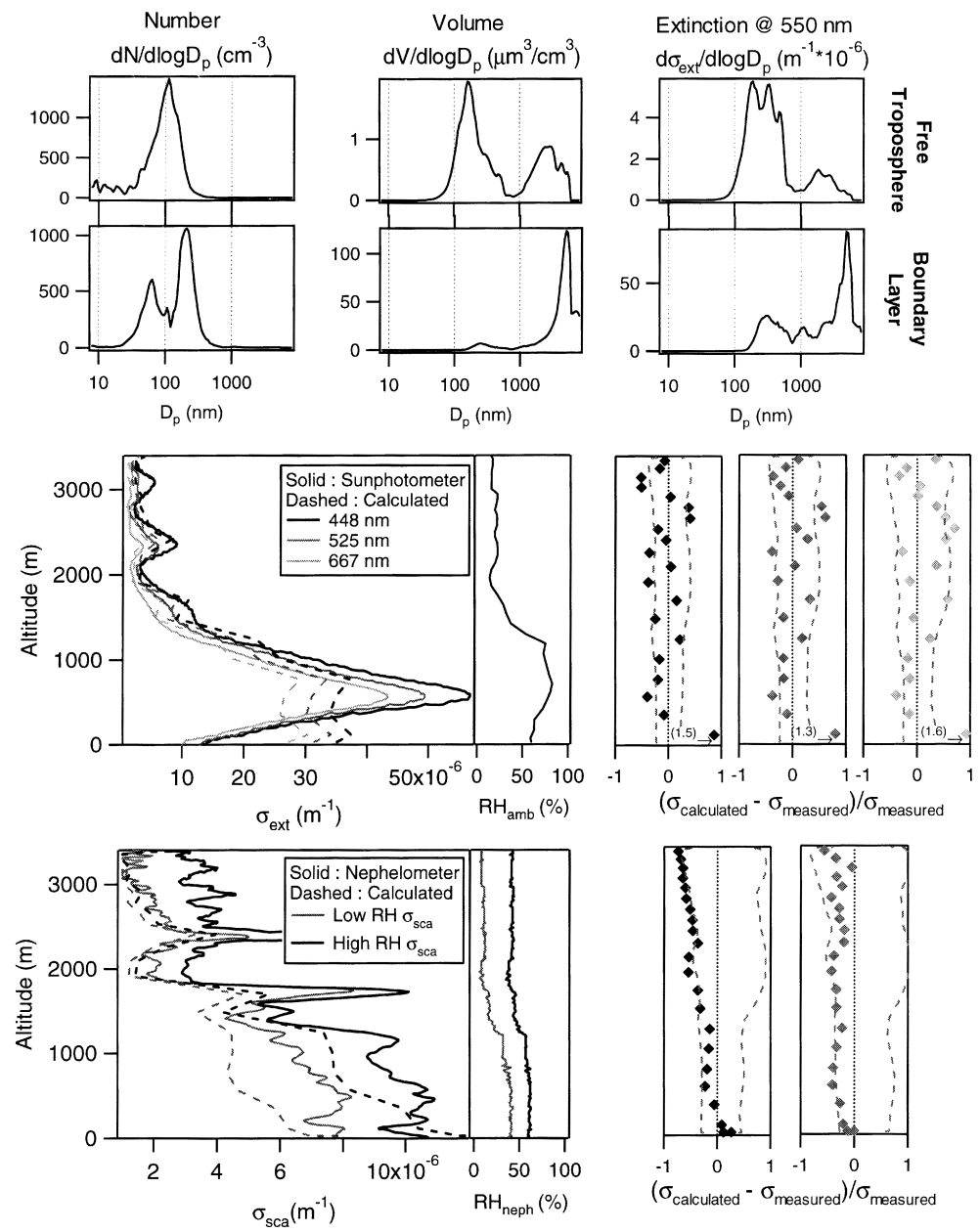

Fig. 8 (cont'd).

days. This mission was, therefore, aimed at analyzing the relatively unperturbed aerosol characteristic of this region, which can then serve as a baseline to which the more anthropogenically or desert influenced aerosols can be compared. To avoid potential island influence, the flight was conducted to the northwest of Tenerife, as is shown on page 1 of Fig. 8. As discussed previously, chemical composition measurements made on Tenerife both in the boundary layer and the free troposphere were used to construct size-resolved aerosol compositions. The assumed compositions shown in Fig. 8 are representative of these relatively clean conditions. In particular, the sub- micron aerosol is composed of a significant fraction of organic carbon, both in the boundary layer and the free troposphere, while elemental carbon constitutes an appreciable fraction only in the free-tropospheric aerosol.

Also shown in Fig. 8 are the relative humidity, pressure altitude, number size distribution, integrated number concentration, and calculated aerosol mass, all as functions of time. Similar to the majority of the measurements made during ACE-2, the size distribution and associated number concentration vary little with time, in both the boundary layer and free troposphere. As was the case for the overall results discussed above, 

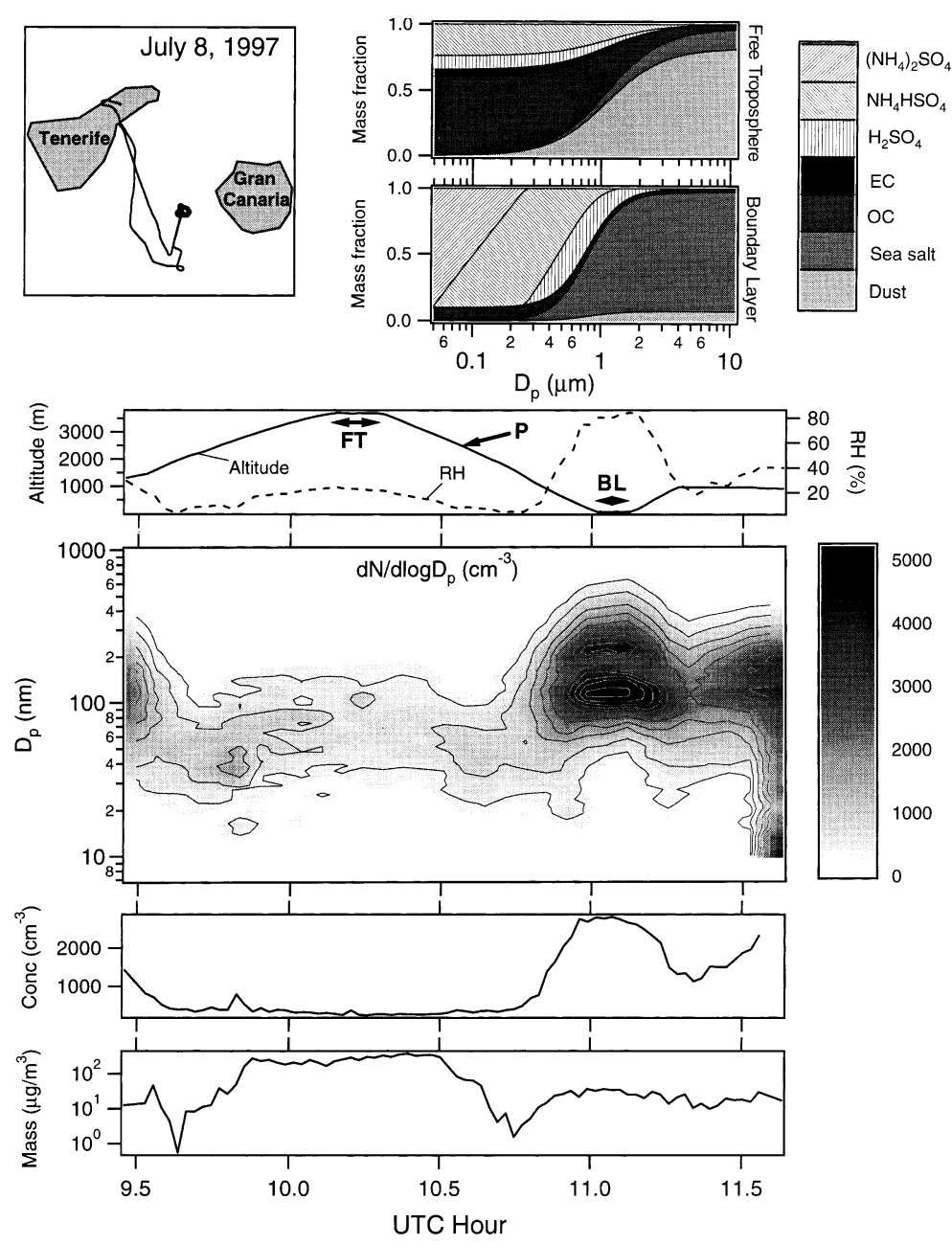

Fig. 9. The same format as in Fig. 8, but for a flight that encountered a polluted boundary layer and a dust layer aloft.

each of the quantities presented, except aerosol mass, is calculated using the adjusted size distributions at ambient relative humidity. As described previously, the free-tropospheric aerosol sampled on this date had a significantly higher number concentration and median diameter than that measured during any of the other flights. This increased concentration does not, however, translate into a significant increase in mass. The sparse, but large, sea salt particles within the boundary layer account for an order of magnitude more mass and extinction than the concentrated, but small, particles within the free troposphere.

Indicated on the plot showing altitude and relative humidity are periods over which the size distributions are averaged. The number, volume, and extinction distributions corresponding to the averaged periods within the free troposphere (FT) and the boundary layer (BL) are shown on page 2 of Fig. 8. The characteristic bimodal boundary layer number distribution and monomodal freetropospheric number distribution are clearly shown. Also indicated on the altitude and humidity plot is the altitude profile $(\mathrm{P})$ used for radiative closure comparisons. For the closure comparisons, the size distributions were averaged over $90 \mathrm{~s}$ to improve upon the resulting counting statistics. This resulted in a vertical resolution of approxi- 

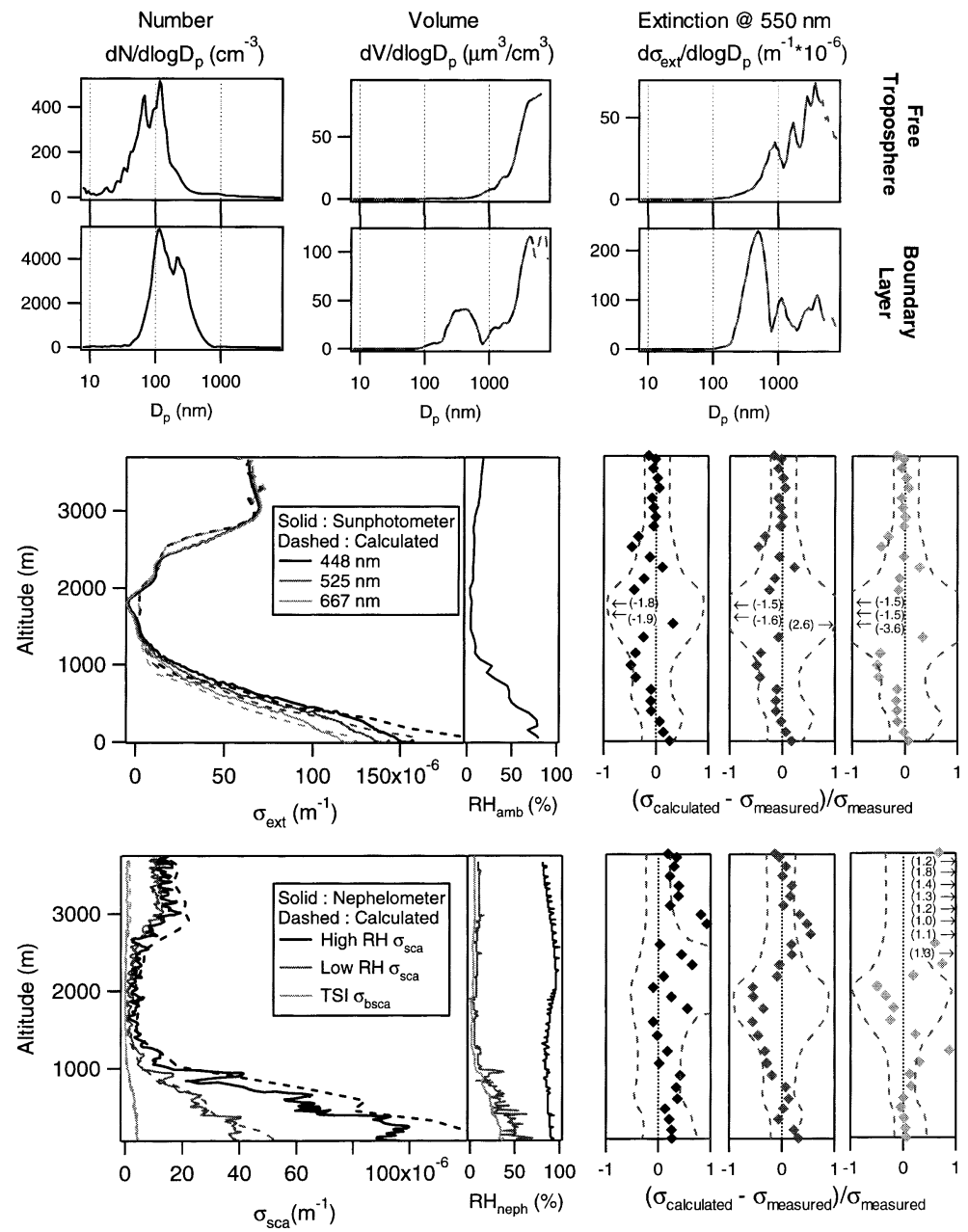

Fig. 9 (cont'd).

mately $175 \mathrm{~m}$ for $30 \mathrm{~min}$ profiles (21 June), $117 \mathrm{~m}$ for $45 \mathrm{~min}$ profiles ( 8 and $17 \mathrm{July}$ ), and $88 \mathrm{~m}$ for 60 min profiles (10 July).

As shown on page 2 of Fig. 8, the columnintegrated extinction coefficients calculated using the size distributions were comparable to those derived using the sunphotometer data. However, relatively large discrepancies exist in the boundary layer where the calculations do not capture a distinct maximum present in the sunphotometer data at approximately $500 \mathrm{~m}$. From the adjacent difference plots, it is clear that this disagreement exceeds that expected for the uncertainties and random errors involved in the measurements for about half of the points of comparison within the boundary layer. Although it is not possible to definitively state which measurement is erroneous, a maximum such as that present in the sunphotometer data could be the result of inaccuracies involved in differentiating the raw signal. This postulation is supported by the absence of a similar maximum in the nephelometer data, although the limited particle size range that successfully penetrates the cyclone could hide such a maximum were it a result of large sea salt particles. Additionally, the apparent agreement between the scattering coefficient of the nephelometer operated at near ambient $\mathrm{RH}$ and the extinction coefficient 

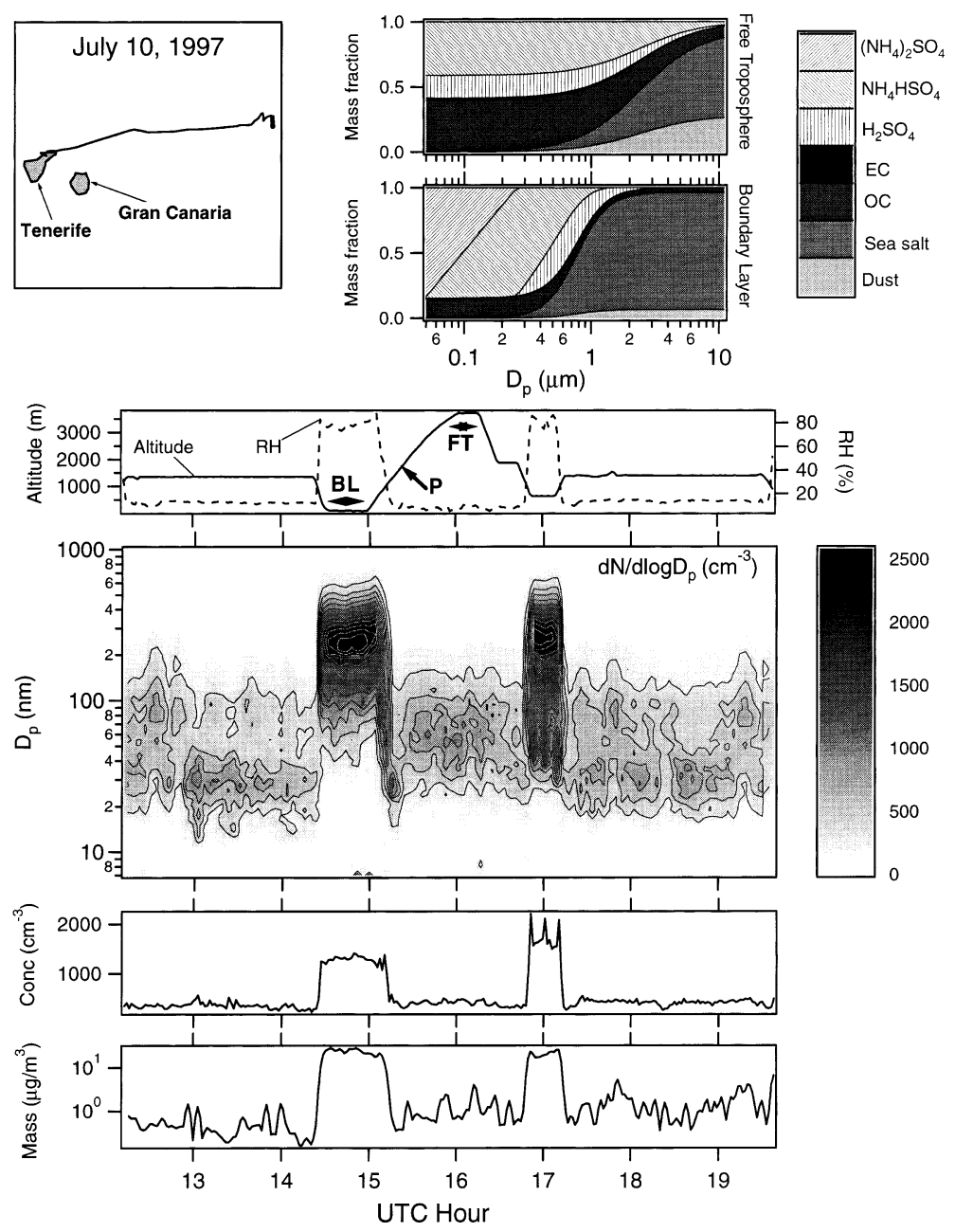

Fig. 10. The same format as in Fig. 8, but for a flight that encountered a polluted boundary layer and no dust layer aloft.

derived by the sunphotometer data near sea level suggests that at least one of the measurements is incorrect, since the nephelometer only measures a subset of the total extinction. The size-distributionbased calculations do appear to capture the measured inverse relationship between extinction and wavelength, a relationship often parameterized as an Ångström coefficient.

Although the maximum discrepancies between the calculated and measured scattering coefficients corresponding to the "wet" and "dry" nephelometers are less than those associated with the sunphotometer comparison, there appears to be a systematic underestimation of the measured values. This is clearly shown in the difference plots associated with the nephelometer comparisons, although most of these points still lie within the range of estimated uncertainties. The calculated increase in the scattering coefficient with increasing relative humidity agrees well with measurements made in the boundary layer, but underestimates those made in the free troposphere. This is most likely the result of inaccurate assumptions concerning the chemical composition of the aerosols or to error incurred by assuming that the organic carbon is non-hygroscopic. 

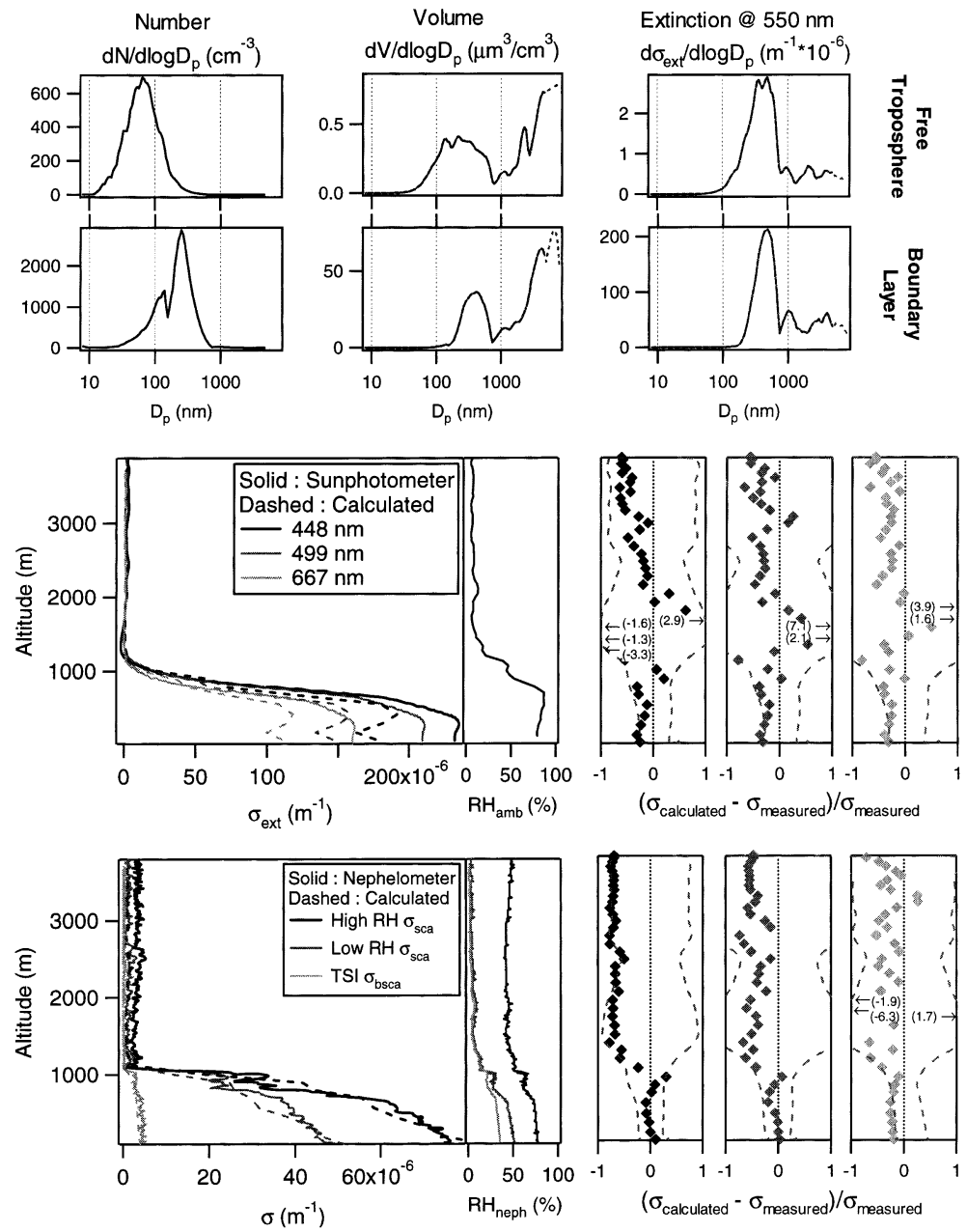

Fig. 10 (cont'd).

8 July 1997. In contrast to the relatively unperturbed boundary layer and free troposphere observed during the 21 June case study, on 8 July the boundary-layer air parcel had passed over much of the Iberian Peninsula while the freetropospheric air parcel originated over Africa. Consistent with expectations, the resulting boundary-layer and free-tropospheric aerosols contained substantial quantities of anthropogenic aerosols and Saharan dust, respectively. As shown in Fig. 9, page 1, the flight was conducted southeast of Tenerife in a cloudless region that was not directly affected by either Tenerife or the adjacent island, Gran Canaria. Measurements made at PDH show an enhanced fractional contribution of the sulfates in continentally influenced aerosols, which is reflected in the size-resolved, assumed composition for the boundary layer. The fine mode aerosol within the free troposphere was predominantly organic carbon, with dust constituting the majority of the coarse mode.

Boundary layer aerosol number concentrations were observed to reach values more than 5 times higher than those measured during the cleaner, 21 June flight, while free-tropospheric aerosol mass loadings were more than 2 orders of magnitude greater than those previously measured. The averaged number, volume, and extinction distributions 

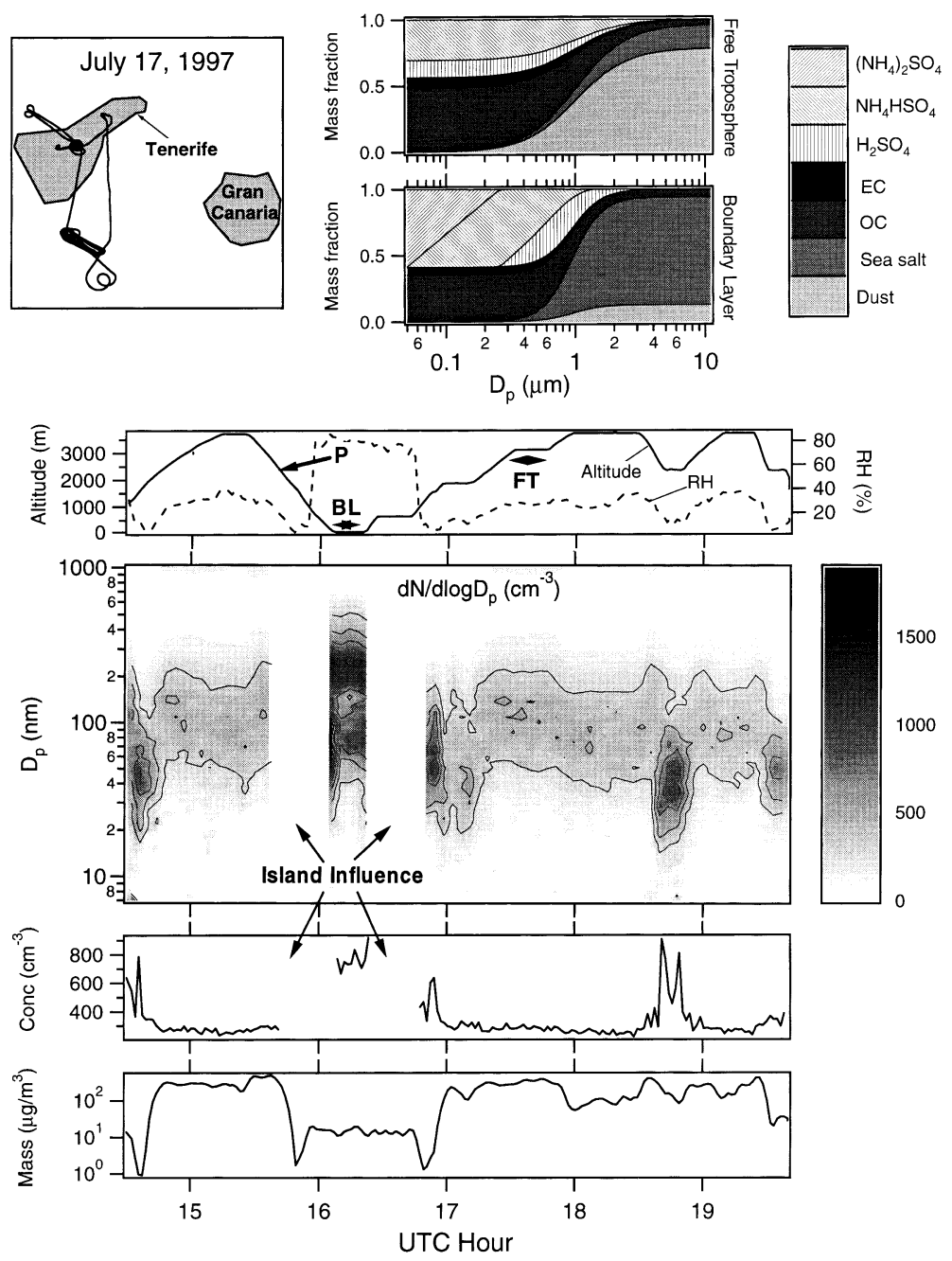

Fig. 11. The same format as in Fig. 8, but for a flight that encountered a clean boundary layer and a dust layer aloft.

show the monomodal submicron aerosol within the boundary layer dominates the overall extinction coefficient, while the coarse dust particles are responsible for essentially all of the extinction in the free troposphere. The calculated aerosol mass, and to a lesser extent, the calculated extinction coefficient, is sensitive to the extrapolation used since the FSSP on the Pelican was inoperable.

Agreement between calculated and measured optical properties of the aerosol for this flight is significantly better than for the 21 June case. Discrepancies associated with the sunphotometer comparisons are within experimental uncertainties both in the boundary layer and the dust layer aloft. Only between these two distinct layers is the disagreement excessive, largely due to the differentiation of sunphotometer data, which resulted in negative extinction coefficients between approximately 1600 and $1900 \mathrm{~m}$. Agreement between the derived and measured scattering coefficients is within specified uncertainties both in the boundary layer, and in the transition between the boundary layer and dust aloft, although a significant amount of scatter is present when the values approach $10^{-6} \mathrm{~m}^{-1}$. More significant discrepancies exist between the nephelometer measurements and size 

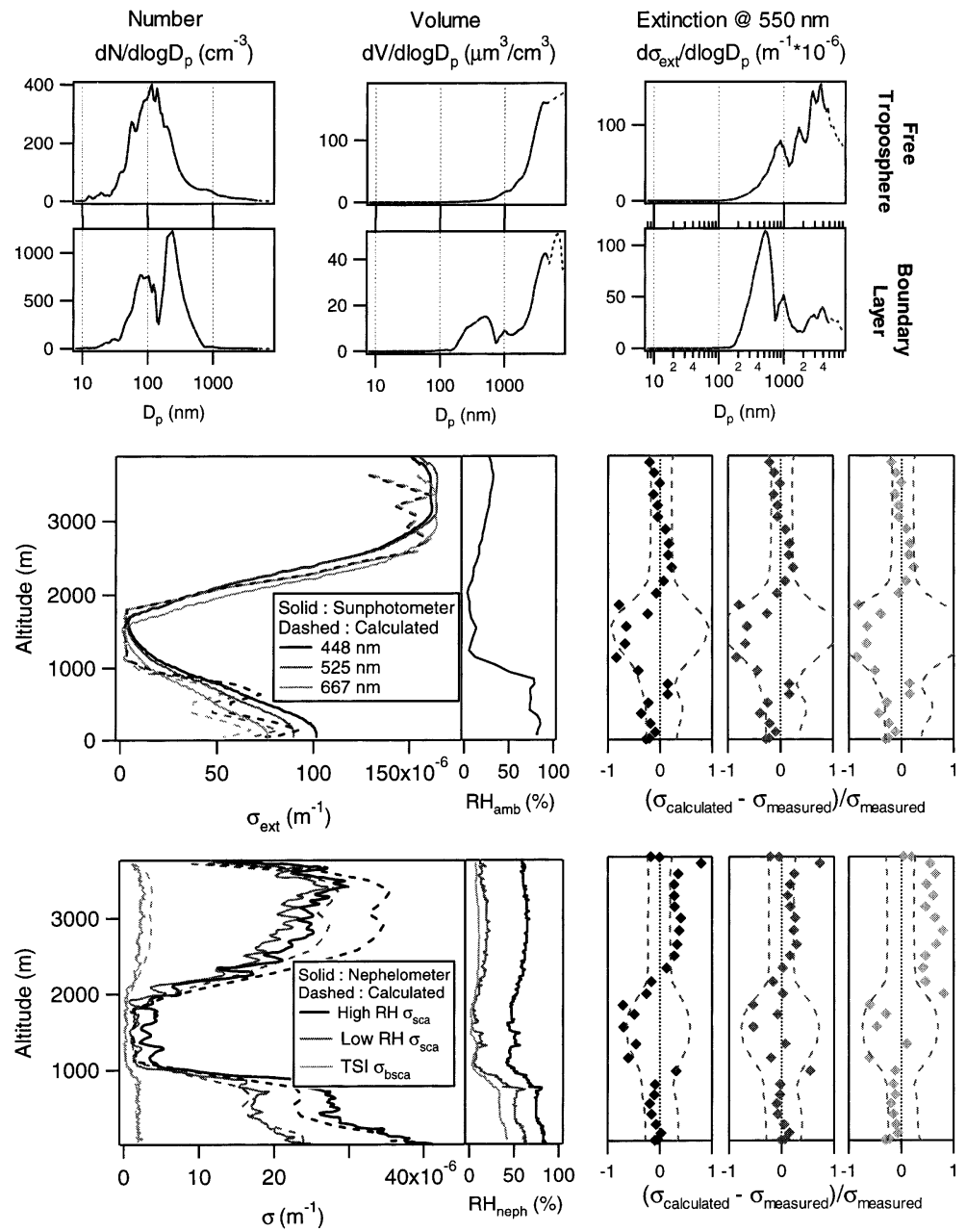

Fig. 11 (cont'd).

distribution calculations in the dust layer. Greater than expected losses within the cyclone, tubing, and nephelometers themselves could account for these discrepancies, although a $15 \%$ decrease in the cyclone cut size was found to be insufficient to result in agreement. Uncertainty concerning the phase functions of nonspherical particles and the impact this would have on the integrated scattering coefficient and, more importantly, the backscattering coefficient could also lead to the observed disagreement.

10 July 1997. The principal focus of the 10 July flight was a sunphotometer intercomparison with the $\mathrm{R} / \mathrm{V}$ Vodyanitsky. As a result, the majority of the flight was a transect to and from the location of the ship, as is shown in the flight track on page 1 of Fig. 10. Similar to the 8 July case study, the boundary-layer aerosol encountered on 10 July was also continentally influenced. Composition measurements made at PDH on this day indicate that the bulk aerosol had characteristics very similar to those observed for the previous case study, with sulfates dominating the submicron mass. However, the number concentration observed was significantly less than on 8 July, while the size distribution was shifted to slightly larger diameters. These 2 effects were found to partially offset one another with respect to the 
optical properties of the aerosol, though. The freetropospheric aerosol was observed to contain little or no mineral dust and contributed negligibly to the total columnar mass or extinction.

Within the boundary layer, extinction coefficients derived from the sunphotometer data were approximately $25 \%$ greater than those calculated based on the size distribution measurements. Agreement with the nephelometers was significantly better, suggesting that the disagreement with the sunphotometer may be a result of larger particles that would not reach the nephelometers, but would affect the sunphotometer measurement. As with approximately half of the flights, no FSSP data were available in this case, and therefore the previously discussed extrapolation could result in an underestimation of the concentration of large, sea salt particles. Scattering and extinction coefficients within the free troposphere were approximately 2 orders of magnitude less than within the boundary layer, resulting in an increase in the importance of the estimated random errors, and an increase in the scatter observed in the difference plots.

17 July 1997. The last of the case studies focused on the properties of a dust layer significantly more effective at light extinction than that encountered during 8 July. KNMI back trajectories suggested that the air parcel arriving in the boundary layer passed adjacent to Europe making no direct contact, while most of the back trajectories arriving in the free troposphere originated over Africa. Since the goal of this mission was to characterize the dust layer, the flight was conducted primarily south of Tenerife where boundary-layer measurements were subject to contamination from the island. This flight track is shown in Fig. 11, page 1. On 2 occasions, the aerosol number concentration reached approximately $10^{4} \mathrm{~cm}^{-3}$, suggesting influence from sources on Tenerife. Size distributions and integrated number concentration corresponding to these events have not been included in the plots to allow for more detail for the uninfluenced data. Measurements of both organic and elemental carbon at IZO were thought to be unreasonably high for this date (J. Putaud, 1998, personal communication) and therefore, the assumed chemical composition was based on the average of the measurements made the previous and following days.

As expected, the coarse Saharan dust particles were observed to account for essentially the entirety of the aerosol mass and extinction coefficient within the free troposphere. The number size distribution within the boundary layer is almost identical to that measured during the 21 June flight. Relative to the 21 June flight, however, the submicron aerosol contributed significantly more to the extinction coefficient.

Results from comparisons between calculated and derived optical properties were similar to those from the 8 July flight, with discrepancies in excess of the estimated uncertainties only for those comparisons with the nephelometers in the dust layer. Some possible explanations for this disagreement are given in the discussion of the 8 July mission. It is not clear whether the variability in the size-distribution-based extinction coefficient as a function of altitude, or the lack thereof in the sunphotometer data, is a true representation of the boundary-layer structure. The ambient relative humidity profile seems to have a shape similar to the calculated values, though much less exaggerated. As has been true in the boundary layer for most of the optical comparisons, the derived extinction coefficients are less than those measured by the sunphotometer.

\section{Summary}

Aerosol-size distributions were measured using a DMA and 2 OPCs during 21 flights conducted as part of the ACE-2 field campaign. Great care was taken to ensure the accuracy of the individual size measurements and of the ultimate integrated distribution to which they contributed. Aerosol characteristics observed in this region were varied, primarily resulting from the extent of contact the surrounding air mass made with Europe or Africa prior to its arrival. To permit description of average aerosol properties, boundary-layer aerosols in this region can generally be categorized as background or continentally influenced, while freetropospheric aerosols can be differentiated on the basis of the presence or absence of a Saharan dust layer. Similar to previous studies conducted in this area, the number size distributions within the boundary layer were found to be bimodal during relatively clean conditions, but possessed only a single, accumulation, mode during more polluted conditions. Free tropospheric aerosols consistently 
had only a single mode that typically peaked below $100 \mathrm{~nm}$ diameter.

Detailed analyses were performed for 4 case studies that, collectively, spanned the range of aerosol types encountered. Of particular interest for these case studies were radiative closure comparisons performed between the verticallyresolved aerosol optical characteristics as determined through the use of the aerosol microphysical data, and those measured directly by a multi-wavelength sunphotometer and 3 nephelometers. While differences did exist between the derived and measured quantities in some cases, in general, the agreement obtained was within the uncertainty expected. Averaged over the 4 case studies, the derived extinction coefficient was $2.5 \%$ greater than that measured by the sunphotometer for measurements made in the clean boundary layer, but was $13 \%, 3.3 \%$, and $17 \%$ less than that measured within the polluted boundary layer, free troposphere with a dust layer, and free troposphere without a dust layer, respectively. For comparisons with the non-humidified nephelometer, the averaged derived scattering coefficient exceeded the measured value by $4.7 \%$ and $17 \%$ in the polluted boundary layer and dust-laden free troposphere, respectively, but was $9.6 \%$ and $41 \%$ less than that measured for background boundary-layer and free-tropospheric aerosols, respectively. The simultaneous agreement with the variety of instruments on board, each of which was sensitive to different aspects of the sampled aerosol population, limits the degree to which potential multiple errors in the size distribution and related analysis could simply offset one another, as might be the case if comparison with a single measurement at a single wavelength were made. It is clear from the case studies that direct comparison between the partial scattering coefficients measured by the nephelometers and the total extinction coefficient derived from the sunphotometer measurements, without careful consideration of the size distributions, would lead to substantial error. Future improvements in the sizing instruments themselves, as well as the simultaneous measurement of time and sizeresolved aerosol chemical composition, will improve the ability to perform in situ radiative closure on the atmospheric aerosol.

\section{Acknowledgements}

This research is a contribution to the International Global Atmospheric Chemistry (IGAC) Core Project of the International Geosphere-Biosphere Programme (IGBP) and is part of the IGAC Aerosol Characterization Experiments (ACE). Primary funding for this work has been provided by the National Science Foundation Grant ATM-9614105, and by the Office of Naval Research Grant N00014-91-0119. Additional funding has been provided by the Office of Naval Research Grant N00014-971-0132, the National Aeronautics and Space Administration, the National Oceanic and Atmospheric Administration, and the European Commission, DG XII.

\section{REFERENCES}

Ackerman, T. P. and Toon, O. B. 1981. Absorption of visible radiation in atmosphere containing mixtures of absorbing and nonabsorbing particles. Appl. Opt. 20, 3661-3667.

Anderson, T. L., Covert, D. S., Marshall, S. F., Laucks, M. L., Charlson, R. J., Waggoner, A. P., Ogren, J. A., Caldow, R., Holm, R. L., Quant, F. R., Sem, G. J., Wiedensohler, A., Ahlquist, N. A. and Bates, T. S 1996. Performance-characteristics of a high-sensitivity, 3-wavelength, total scatter/backscatter nephelometer. J. Atmos. Ocean Technol. 13, 967-986.

Biswas, P., Jones, C. L. and Flagan, R. C. 1987. Distortion of size distributions by condensation and evaporation in aerosol instruments. Aerosol Sci. Technol. 7, 231-246.

Brenguier, J. L., Chuang, P. Y., Fouquart, Y., Johnson,
D. W., Parol, F., Pawlowska, H., Pelon, J., Schüller, L., Schröder, F. and Snider, J. 2000. An overview of the ACE-2 CLOUDYCOLUMN closure experiment. Tellus 52B, 815-829.

Cachier, H., Buat-Ménard, P., Fontugne, M. and Chesselet, R. 1986. Long-range transport of continentallyderived particulate carbon in the marine atmosphere: Evidence from stable carbon isotope studies. Tellus 38B, 161-177.

Clarke, A. D., Porter, J. N., Valero, F. P. J. and Pilewskie, P. 1996. Vertical profiles, aerosol microphysics, and optical closure during the Atlantic Stratocumulus Transition Experiment - measured and modeled column optical-properties. J. Geophys. Res. 101, 4443-4453.

Gassó, S., Hegg, D. A., Covert, D. S., Collins, D. R.,

Tellus 52B (2000), 2 
Noone, K. J., Öström, E., Schmid, B., Russell, P. B., Livingston, J. M., Durkee, P. A., Jonsson, H. and Jonsson, H. H. 2000. Influence of humidity on the aerosol scattering coefficient and its effect on the upwelling radiance during ACE-2. Tellus 52B, 546-567.

Hegg, D. A., Livingston, J., Hobbs, P. V., Novakov, T. and Russell, P. 1997. Chemical apportionment of aerosol column optical depth off the mid-Atlantic coast of the United States. J. Geophys. Res. 102, 25,293-25,303.

Hoff, R. M., Guisebagley, L., Staebler, R. M., Wiebe, H. A., Brook, J., Georgi, B. and Dusterdiek, T. 1996 Lidar, nephelometer, and in-situ aerosol experiments in Southern Ontario. J. Geophys. Res. 101, 19,199-19,209.

Hoppel, W. A., Frick, G. M. and Larson, R. E. 1986. Effect of non-precipitating clouds on the aerosol-size distribution in the marine boundary-layer. Geophys. Res. Lett. 13, 125-128.

Howell, S. G. and Huebert, B. J. 1998. Determining marine aerosol scattering characteristics at ambient humidity from size-resolved chemical-composition. J. Geophys. Res. 103, 1391-1404.

Jensen, T. L., Kreidenweis, S. M., Kim, Y., Sievering, H. and Pszenny, A. 1996. Aerosol distributions in the North-Atlantic marine boundary-layer during Atlantic Stratocumulus Transition Experiment Marine Aerosol and Gas-Exchange. J. Geophys. Res. 101, 4455-4467.

Johnson, D. W., Osborne, S., Wood, R., Suhre, K., Johnson, R., Businger, S., Quinn, P. K.,, Wiedensohler, A., Durkee, P. A., Russell, L. M., Andreae, M. O., O'Dowd, C., Noone, K. J., Bandy, B., Rudolph, J. and Rapsomanikis, S. 2000. An overview of the Lagrangian experiments undertaken during the North Atlantic regional Aerosol Characterization Experiment (ACE-2). Tellus 52B, 290-320.

Larson, S. M., Cass, G. R., Hussey, K. J. and Luce, F. 1988. Verification of image-processing based visibility models. Environ. Sci. Technol. 22, 629-637.

Mishchenko, M. I., Travis, L. D., Kahn, R. A. and West, R. A. 1997. Modeling phase functions for dustlike tropospheric aerosols using a shape mixture of randomly oriented polydisperse spheroids. J. Geophys. Res. 102, 16,831-16,847.

Moelwyn-Hughes, E. A. 1961. Physical chemistry. Tarrytown, New York: Pergamon.

Öström, E. and Noone, K. J. 2000. Vertical profiles of aerosol scattering and absorption measured in situ during the North Atlantic Aerosol Characterization Experiment. Tellus 52B, 526-545.

Patterson, E. M., Gillette, D. A. and Stockton, B. H 1977. Complex index of refraction between 300 and $700 \mathrm{~nm}$ for Saharan aerosols. J. Geophys. Res. 82, 3153-3160.

Pruppacher, H. R. and Klett, J. D. 1980. Microphysics of clouds and precipitation. Dordrecht: Kluwer Academic Publishers.

Putaud, J. P., VanDingenen, R., Mangoni, M., Virkkula,
A., Raes, F., Maring, H., Prospero, J. M., Swietlicki, E., Berg, O. H., Hillamo, R. and Makela, T. 2000. Chemical mass closure and origin assessment of the submicron aerosol in the marine boundary layer and the free troposphere at Tenerife during ACE-2. Tellus 52B, 141-168.

Raes, F., Bates, T., McGovern, F. M. and Liedekerke, M. V. 2000. The second Aerosol Characterization Experiment (ACE-2): General overview and main results. Tellus 52B, 111-126.

Raes, F., Vandingenen, R., Cuevas, E., Vanvelthoven, P. F. J. and Prospero, J. M. 1997. Observations of aerosols in the free troposphere and marine boundarylayer of the subtropical Northeast Atlantic - discussion of processes determining their size distribution. J. Geophys. Res. 102, 21,315-21,328.

Redemann, J., Turco, R. P., Pueschel, R. F., Fenn, M. A., Browell, E. V. and Grant, W. B. 1998. A multi-instrument approach for characterizing the vertical structure of aerosol properties - case-studies in the Pacific basin troposphere. J. Geophys. Res. 103, 23,287-23,298.

Russell, L. M., Huebert, B. J., Flagan, R. C. and Seinfeld, J. H. 1996a. Characterization of submicron aerosolsize distributions from time-resolved measurements in the Atlantic Stratocumulus Transition Experiment Marine Aerosol and Gas-Exchange. J. Geophys. Res. 101, 4469-4478.

Russell, L. M., Zhang, S. H., Flagan, R. C., Seinfeld, J. H., Stolzenburg, M. R. and Caldow, R. 1996b. Radially classified aerosol detector for aircraft-based submicron aerosol measurements. J. Atmos. Ocean Technol. 13, 598-609.

Russell, P. B. and Heintzenberg, J. 2000. An overview of the ACE-2 clear sky column closure experiment (CLEARCOLUMN). Tellus 52B, 463-483.

Saxena, P., Hildemann, L. M., McMurry, P. H. and Seinfeld, J. H. 1995. Organics alter hygroscopic behavior of atmospheric particles. J. Geophys. Res. 100, $18,755-18,770$.

Schmeling, M., Russell, L. M., Erlick, C., Collins, D. R., Jonsson, H. H., Wang, Q., Kregsamer, P. and Streli, C. 2000. Aerosol particle chemical characteristics measured from aircraft in the lower troposphere during ACE-2. Tellus 52B, 185-200.

Schmid, B., Livingston, J. M., Russell, P. B., Durkee, P. A., Jonsson, H. H., Collins, D. R., Flagan, R. C., Seinfeld, J. H., Gassó, S., Hegg, D. A., Öström, E., Noone, K. J., Welton, E. J., Voss, K., Gordon, H. R., Formenti, P. and Andreae, M. O. 2000. Clear sky closure studies of lower tropospheric aerosol and water vapor during ACE-2 using airborne sunphotometer, airborne in-situ, space-borne, and groundbased measurements. Tellus 52B, 568-593.

Seinfeld, J. H. and Pandis, S. N. 1998. Atmospheric chemistry and physics. New York: Wiley-Interscience.

Swietlicki, E., Zhou, J., Covert, D. S., Hameri, K., Busch, B., Vakeva, M., Dusek, U., Berg, O. H., Wiedensohler, A., Aalto, P., Makela, J., Marinsson, B. G., 
Papaspiropoulos, G., Mentes, B., Frank, G. and Stratmann, F. 2000. Hygroscopic properties of aerosol particles in the Northeastern Atlantic during ACE-2. Tellus 52B, 201-227.

Tang, I. N. 1996. Chemical and size effects of hygroscopic aerosols on light-scattering coefficients. J. Geophys. Res. 101, 19,245-19,250.

Tang, I. N. and Munkelwitz, H. R. 1994. Water activities, densities, and refractive-indexes of aqueous sulfates and sodium-nitrate droplets of atmospheric importance. J. Geophys. Res. 99, 18,801-18,808.
Tang, I. N., Tridico, A. C. and Fung, K. H. 1997. Thermodynamic and optical-properties of sea-salt aerosols. J. Geophys. Res. 102, 23,269-23,275.

Tegen, I. and Fung, I. 1994. Modeling of mineral dust in the atmosphere - sources, transport, and opticalthickness. J. Geophys. Res. 99, 22,897-22,914.

Verver, G., Raes, F., Vogelezang, D. and Johnson, D. W. 2000. The second Aerosol Characterization Experiment (ACE-2): Meteorological and chemical context. Tellus 52B, 126-140. 